\title{
Article
}

\section{A critical review of adverse effects to the kidney: mechanisms, data sources and in silico tools to assist prediction}

Pletz, J, Enoch, S.J, Jais, D.M, Mellor, Claire, Pawar, G, Madden, J.C, Webb, S.D, Tagliati, C and Cronin, M.T.D

Available at http://clok.uclan.ac.uk/24644/

Pletz, J, Enoch, S.J, Jais, D.M, Mellor, Claire ORCID: 0000-0002-7647-2085, Pawar, G, Madden, J.C, Webb, S.D, Tagliati, C and Cronin, M.T.D (2018) A critical review of adverse effects to the kidney: mechanisms, data sources and in silico tools to assist prediction. Expert Opinion on Drug Metabolism \& Toxicology . ISSN 1742-5255

It is advisable to refer to the publisher's version if you intend to cite from the work.

For more information about UCLan's research in this area go to

http://www.uclan.ac.uk/researchgroups/ and search for <name of research Group>.

For information about Research generally at UCLan please go to http://www.uclan.ac.uk/research/

All outputs in CLoK are protected by Intellectual Property Rights law, including Copyright law. Copyright, IPR and Moral Rights for the works on this site are retained by the individual authors and/or other copyright owners. Terms and conditions for use of this material are defined in the policies page. 
A CRITICAL REVIEW OF ADVERSE EFFECTS TO THE KIDNEY: MECHANISMS, DATA SOURCES AND IN SILICO TOOLS TO ASSIST PREDICTION

J. Pletz ${ }^{1}$, S.J. Enoch ${ }^{1}$, D.M. Jais ${ }^{1}$, C.L. Mellor ${ }^{1}$, G. Pawar ${ }^{1}$, J.C. Madden ${ }^{1}$, S. D. Webb ${ }^{2}$, C. Tagliati ${ }^{3}$, M.T.D. Cronin*1

${ }^{1}$ School of Pharmacy and Biomolecular Sciences, Liverpool John Moores University, Byrom Street, Liverpool L3 3AF, England 2Department of Applied Mathematics, Liverpool John Moores University, Liverpool, England ${ }^{3}$ Departamento de Análises Clínicas e Toxicológicas, Universidade Federal de Minas Gerais, Belo Horizonte, Brazil

*Corresponding author: Tel. +44 151231 2402; e-mail address: M.T.Cronin@ljmu.ac.uk (Mark Cronin) 


\section{ABSTRACT}

Introduction: The kidney is a major target for toxicity elicited by pharmaceuticals and environmental pollutants. Standard testing which often does not investigate underlying mechanisms has proven not to be an adequate hazard assessment approach. As such, there is an opportunity for the application of computational approaches that utilise multi-scale data based on the Adverse Outcome Pathway (AOP) paradigm, coupled with an understanding of the chemistry underpinning the molecular initiating event (MIE) to provide a deep understanding of how structural fragments of molecules relate to specific mechanisms of nephrotoxicity.

The aim of this investigation was to review the current scientific landscape related to computational methods, including mechanistic data, AOPs, publicly available knowledge bases and current in silico models, for the assessment of pharmaceuticals and other chemicals with regard to their potential to elicit nephrotoxicity. A list of over 250 nephrotoxicants enriched with, where possible, mechanistic and AOP-derived understanding was compiled.

Expert opinion: Whilst little mechanistic evidence has been translated into AOPs, this review identified a number of data sources of in vitro, in vivo and human data that may assist in the development of in silico models which in turn may shed light on the inter-relationships between nephrotoxicity mechanisms.

Key words: kidney, nephrotoxicity, in silico, computational models, (Q)SAR, mechanisms 


\subsection{INTRODUCTION}

Acute renal failure in critically ill patients, as well as those with chronic kidney disease, was related to drug therapy in about $20 \%$ and $35 \%$ of cases reported respectively [1-3]. As a result of such toxicity, six prescription drugs (beta-ethoxy-lacetanilanide, bucetin, phenacetin, suprofen, thiobutabarbitone and zomepirac) were withdrawn from the market between 1983 and 1993, at great cost, due to renal adverse events, solely or in combination with other adverse effects [4]. Therefore, eliminating drug candidates which cause these adverse effects at early stages of drug design is extremely important to ensure patient safety. However, despite its importance for drug development and for many other industrial sectors, nephrotoxicity is a complex endpoint and often occurs gradually or as a complication related to other pathologies such as diabetes [5] and hypertension [6], thus making it difficult to identify even with sophisticated toxicity testing or clinical trials.

Established approaches to identify kidney toxicants have traditionally relied on extensive animal testing. However, the "Toxicity Testing in the $21^{\text {st }}$ Century" paradigm calls for use of alternative testing strategies [7]. Computational approaches such as (quantitative) structure-activity relationships ((Q)SARs) $)^{1}$ and structural alerts (SAs) are currently used to predict a variety of organ toxicities e.g. for hepatic toxicity [8]. In recent years, much emphasis has been placed on understanding the underlying mechanisms of liver toxicity which have led to the development of several Adverse Outcome Pathways (AOPs), many SAs and QSARs [8-10]. The relative successes with the development of alternatives for identifying liver toxicants has demonstrated that success can be achieved and it is possible to address other organ level toxicity in a similar manner. Thus, there is a growing movement to other important organs in the body in order to reach the ultimate goal of mapping the toxicological pathways of pharmaceuticals, cosmetics and other chemicals within humans [11].

The kidney is a major target for toxicity elicited by pharmaceuticals and environmental pollutants. Approximately $20 \%$ of acquired acute kidney injury (AKI) cases are associated with the use of drugs [12]. Being burdened with multiple comorbidities, the average patient tends to take several medications which may cause kidney injury [13]. Environmental chemicals including certain heavy metals, trichloroethylene, and bromobenzene have been known to cause nephrotoxic effects [14]. One of the reasons for the kidney being a key target of toxicity may be related to the kinetics of

\footnotetext{
${ }^{1}$ In this paper, (Q)SAR will be mentioned if both SAR and QSAR are referred to while SAR and QSAR are stated to refer to either approach specifically.
} 
many xenobiotic substances. High exposures are reached because of a high blood flow in the kidneys and extensive reabsorption, predominantly in the proximal tubule.

Considering that renal toxicity is a major drug safety issue, standard testing which often does not investigate underlying mechanisms has proven not to be an adequate assessment approach. As such, this is an opportunity for the application of computational approaches that utilise the AOP paradigm coupled with an understanding of the chemistry underpinning the MIE $[10,15]$ to provide a deep understanding of how structural fragments of molecules relate to specific mechanisms of nephrotoxicity. In addition in silico approaches using multi-scale data have been demonstrated to provide valuable insight into hepatotoxicity pathways and the assessment of inter-individual variability $[16,17]$. Multi-scale models incorporate data which span various biological scales, i.e. population, individual whole body, tissue and multi-cellular, and sub-cellular metabolic and signalling pathways [18]. As multi-scale modelling answered some of the pressing questions regarding adverse events in the liver, it is likely to hold the same potential for kidney and bladder related toxicity.

The aim of this investigation was to review the current scientific landscape related to computational methods for the assessment of pharmaceuticals and other chemicals with regard to their potential to elicit nephrotoxicity and to provide a future perspective for this field of research. Here, the term "nephrotoxicity" includes both kidney toxicity and bladder disorders. To achieve the aim, the current data relating to this endpoint, which are accessible in publicly available knowledge bases and could aid the development of computational methods for this toxicity endpoint, were also reviewed. In addition, current in silico models (SAs, QSARS, mechanistic models) related to nephrotoxicity were examined and existing knowledge of relevant toxic mechanisms assessed in order to understand to which extent these have already been covered by existing approaches, including AOPs. Clinical manifestations of renal disease including oedema, uraemia, hyperphosphatemia, hyperkalaemia, hypocalcaemia, acidosis, hyperparathyroidism, and anaemia [19] go beyond the scope of this study and, therefore, were not considered. As uses of in silico toxicology approaches are ever increasing, this investigation also attempted to assess to what extent future models may inform hazard assessments and drug design, and what is needed to drive this field forward.

\subsection{MECHANISMS OF KIDNEY AND BLADDER TOXICITY}


In order to understand the highly specific adverse effects that may take place in the kidney and associated organs, it is essential to appreciate its function and physiology. The key function of the kidney is to eliminate endogenous waste products, control and maintain volume levels, endocrine function, electrolyte content and acid-base balance [20,21]. As major site of elimination of drugs and other chemical compounds, the kidney is a common target for toxicity. Since the kidney is highly vascularised, receiving about $25 \%$ of the resting cardiac output, it is exposed to exogenous compounds in large quantities through systemic circulation $[20,22]$. The functional units of the kidney are nephrons - each kidney contains around one million nephrons, which consist of the glomerulus - a ball of capillaries -, Bowman's capsule, and the tubular element (proximal tubule, Loop of Henle, distal tubule and collecting duct). When a substance reaches the glomerulus through the afferent arteriole it is likely to be filtered into the proximal tubules where the vast majority is reabsorbed back into the blood [23]. Compound accumulation and "local" toxic metabolite formation may occur, making the kidney vulnerable to toxicity via various and simultaneously occurring mechanisms $[12,20,22]$.

As a result of the physiology, there are four main mechanisms of drug-induced renal toxicity which are most commonly manifested as acute kidney injury, namely haemodynamic alteration, (proximal and distal) tubular cell toxicity, (tubular, interstitial, tubulo-interstitial and glomerular) nephritis and tubular obstruction $[24,25]$. Comparatively little is known about bladder toxicity as a whole and less about its underlying mechanisms. However, an understanding of mechanisms, such as it is, will assist in the development of in silico models as well as the organisation of the associated data. Figure 1 shows the sites of the main mechanisms of chemical-induced kidney toxicity.

A consideration of mechanistic toxicology also provides the opportunity to link to relevant Adverse Outcome Pathways (AOPs). The AOP framework facilitates the organisation of mechanistic knowledge and grants validity and robustness to data included in the OECD-sponsored AOP Knowledge Base (AOP-KB), [26, http://aopkb.org]. Mechanistic data gathered and organised in the form of AOPs serve as a robust basis for the development of computational toxicology models $[10,27]$. If an MIE and/or Key Events (KEs) have been defined and respective data are available, a prediction approach to estimate a substance's potential to elicit one of more of these may be achieved using the knowledge in the AOP-KB and the public literature. Table 1 provides a starting point for in silico analyses based around the MIE in particular. The individual endpoints and apical effects are described in more detail in the remainder of Section 2. Additionally, AOPs may aid the grouping of chemicals for read-across [10]. Only a handful of kidney and bladder related AOPs have 
been developed and proposed so far which implies that only a small amount of MIEs and KEs have been defined. Table 1 provides an overview of relevant AOPs that exist at the time of manuscript preparation, as sourced from the AOP Wiki [28, https://aopwiki.org], which is one key resource. 
Figure 1: Sites and mechanisms of chemical-induced renal toxicity and respective substances potentially causing an effect at each [adapted from 25].

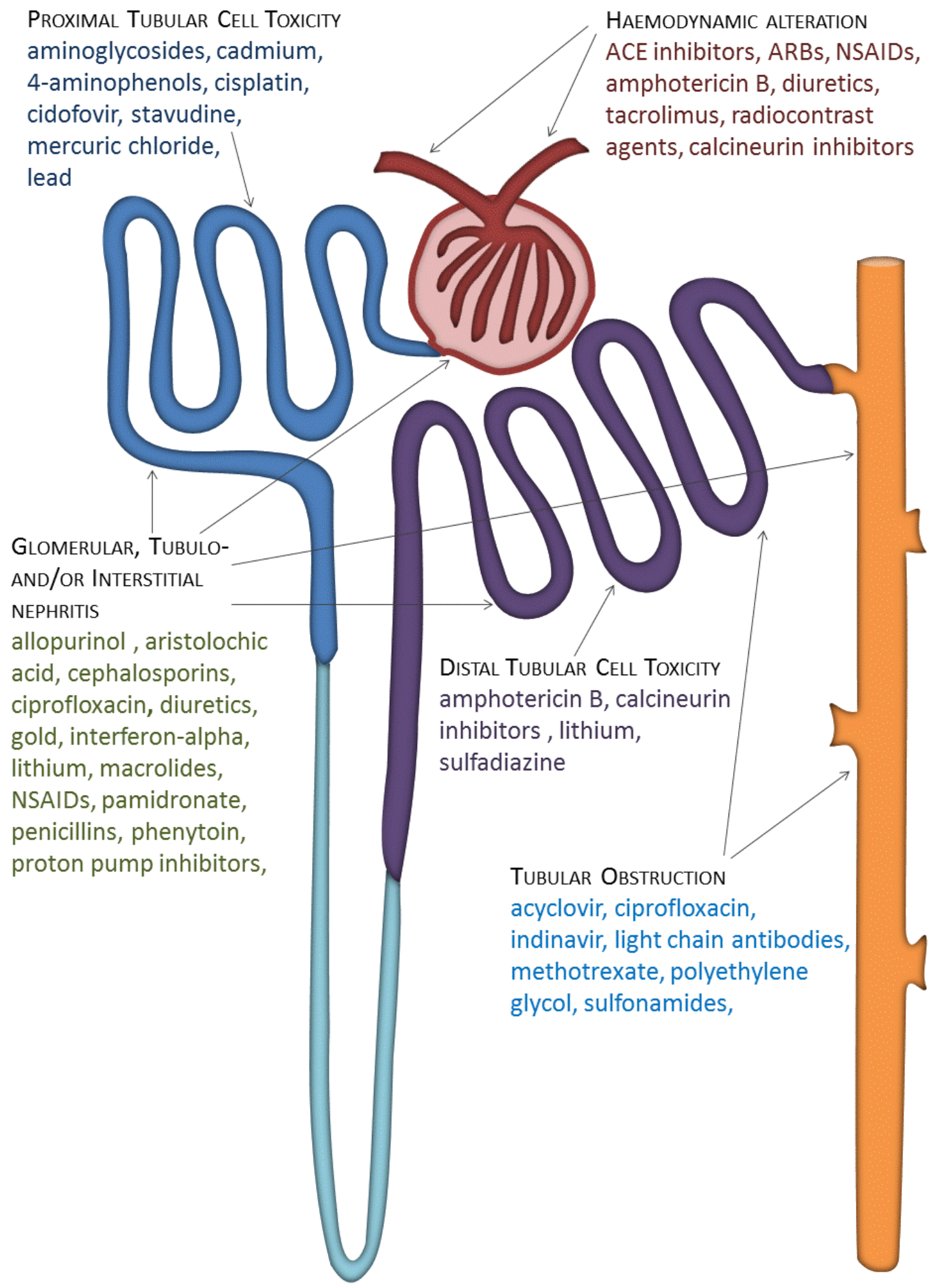


Table 1: Mechanisms of kidney toxicity, related (groups of) substances, and established and proposed MIEs and AOPs directly or indirectly associated with kidney toxicity

\begin{tabular}{|c|c|c|c|c|c|}
\hline Mechanism & Overview & MIE & AOP & Compounds & Biomarkers \\
\hline \multirow{5}{*}{$\begin{array}{l}\text { Haemodynamic } \\
\text { alteration }\end{array}$} & \multirow{5}{*}{$\begin{array}{l}\text { Impaired } \\
\text { autoregulatory } \\
\text { capacity of the renal } \\
\text { vasculature to } \\
\text { vasodilate } \\
\text { vasoconstrict } \\
\text { leading to a reduced } \\
\text { GFR }\end{array}$} & $\begin{array}{l}\text { COX-1 and/or COX-2 inhibition leading to reduced } \\
\text { prostaglandin synthesis and uncontrolled renal } \\
\text { vasoconstriction (aspirin, other NSAIDs, calcineurin } \\
\text { inhibitors) }[29,30]\end{array}$ & AOP proposed by Lhasa Ltd. [29] & \multirow{5}{*}{$\begin{array}{l}\text { ACE inhibitors, ARBs, } \\
\text { NSAIDs (e.g. aspirin), } \\
\text { amphotericin B, tacrolimus, } \\
\text { radiocontrast agents, } \\
\text { calcineurin inhibitors } \\
\text { (cyclosporine, tacrolimus) } \\
{[12,25]}\end{array}$} & \multirow{5}{*}{$\begin{array}{l}\text { (L-18'), lipocalin } 2 \\
(\mathrm{LCN}-2 \text { aka NGAL) } \\
{[31]}\end{array}$} \\
\hline & & $\begin{array}{l}\text { Prevention of formation of angiotensin II (ACE } \\
\text { inhibitors) [32] }\end{array}$ & No AOP found & & \\
\hline & & $\begin{array}{l}\text { Blockage of angiotensin II type } 1 \text { (AT1) receptors } \\
\text { (ARBs) [33] }\end{array}$ & No AOP found & & \\
\hline & & $\begin{array}{l}\text { Increase endothelin and thromboxane and activation } \\
\text { of the renin-angiotensin system (RAS) } \\
\text { (vasoconstriction), and reduction prostacyclin, } \\
\text { prostaglandin E2 and nitric oxide (NO) (vasodilation) } \\
\text { (calcineurin inhibitors) [30] }\end{array}$ & No AOP found & & \\
\hline & & $\begin{array}{l}\text { Changing vascular smooth muscle cell permeability, } \\
\text { cell depolarization with resultant opening of voltage- } \\
\text { dependent calcium channels and muscle cell } \\
\text { contraction (potential mechanism for amphotericin B) } \\
{[34,35]}\end{array}$ & No AOP found & & \\
\hline & & $\begin{array}{l}\text { Metabolisation by oxidase in hepatocyte to } \\
\text { benzoquinoneimine, followed by formation of GSH S- } \\
\text { conjugates (4-aminophenol) [36] }\end{array}$ & $\begin{array}{l}\text { OECD ENV/JM/MONO(2011)8: } \\
\text { Nephrotoxicity induced by } 4- \\
\text { aminophenols [36] }\end{array}$ & & \\
\hline & & $\begin{array}{l}\text { Mitochondrial toxicity pathways: } \\
\text { a) Mitochondrial DNA incorporation (stavudine, }\end{array}$ & $\begin{array}{l}\text { AOP proposed by Lhasa Ltd. } \\
\text { (stavudine, cidofovir) [37] }\end{array}$ & & 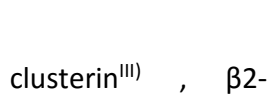 \\
\hline
\end{tabular}




\begin{tabular}{|c|c|c|c|c|c|}
\hline \multirow{3}{*}{$\begin{array}{l}\text { Proximal and } \\
\text { distal tubular } \\
\text { cell toxicity }\end{array}$} & \multirow{3}{*}{$\begin{array}{l}\text { Extensive cellular } \\
\text { uptake and intra- } \\
\text { cellular } \\
\text { accumulation } \\
\text { inducing } \\
\text { compromised } \\
\text { mitochondrial } \\
\text { respiration, } \\
\text { oxidative stress, and } \\
\text { the activation of } \\
\text { intrinsic apoptotic } \\
\text { and necrotic } \\
\text { pathways }\end{array}$} & $\begin{array}{l}\text { cidofovir) [37] } \\
\text { b) Mitochondrial DNA polymerase gamma inhibition } \\
\text { (stavudine, cidofovir) [37] } \\
\text { c) Depletion of SH-groups leading to ROS induction } \\
\text { (cisplatin) [44] }\end{array}$ & & \multirow{3}{*}{$\begin{array}{l}\text { aminoglycoside antibiotics, } \\
\text { amphotericin B, } 4- \\
\text { aminophenols, cisplatin, } \\
\text { nucleotide and nucleoside } \\
\text { antivirals (stavudine, } \\
\text { cidofovir) }[25,36,37]\end{array}$} & \multirow{3}{*}{ 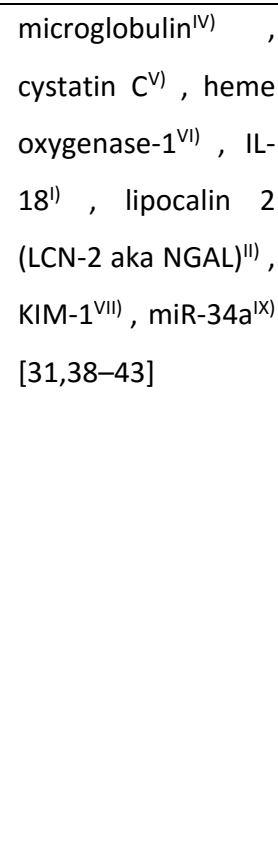 } \\
\hline & & $\begin{array}{l}\text { Accumulation-induced lysosomal effects: } \\
\text { a) accumulation induced lysosomal leakage leading to } \\
\text { tubular dysfunction (aminoglycosides) [45] } \\
\text { b) fusion of compound-containing pinocytic vacuoles } \\
\text { and lysosomes causing osmotic nephrosis (contrast } \\
\text { agents) [46] }\end{array}$ & \multirow{2}{*}{$\begin{array}{l}\text { No AOP found } \\
\text { No AOP found }\end{array}$} & & \\
\hline & & $\begin{array}{l}\text { After moving through cellular membrane, } \\
\text { polyunsaturated region participates in auto-oxidation, } \\
\text { lipid peroxidation and cell membrane damage; forming } \\
\text { pores (amphotericin B) }[34,35]\end{array}$ & & & \\
\hline \multirow{4}{*}{$\begin{array}{l}\text { Tubular, } \\
\text { interstitial, } \\
\text { tubulo- } \\
\text { interstitial and } \\
\text { glomerular } \\
\text { nephritis }\end{array}$} & \multirow{4}{*}{$\begin{array}{l}\text { Inflammatory } \\
\text { changes in the } \\
\text { glomerulus, } \\
\text { interstitial and } \\
\text { tubular cells } \\
\text { predominantly } \\
\text { caused by immune }\end{array}$} & $\begin{array}{l}\text { Interaction with hOAT1 and 3, accumulation within } \\
\text { proximal tubule cells, followed by } \\
\text { uncoupling/inhibition of mitochondrial oxidative } \\
\text { phosphorylation and tubular/papillary necrosis } \\
\text { (aspirin)*[29] }\end{array}$ & AOP proposed by Lhasa Ltd. [29] & \multirow{4}{*}{$\begin{array}{l}\text { NSAIDs (indomethacin, } \\
\text { phenylbutazone, } \\
\text { mefenamic acid, aspirin); } \\
\text { antibiotics (cephalosporins, } \\
\text { ciprofloxacin, ethambutol, } \\
\text { isoniazid, macrolides, } \\
\text { penicillins, rifampicin, } \\
\text { tetracycline); loop } \\
\text { (furosemide), potassium- } \\
\text { sparing (triamterene) and } \\
\text { thiazide diuretics; proton }\end{array}$} & \multirow[b]{4}{*}{$\begin{array}{l}\text { (L-18); lipocalin } 2 \\
\text { (LCN-2 aka NGAL)" }\end{array}$} \\
\hline & & $\begin{array}{l}\text { Production of inflammatory response triggering TNF- } \alpha \\
\text { (cisplatin) }[44,53]\end{array}$ & No AOP found & & \\
\hline & & $\begin{array}{l}\text { Formation of immune complex deposits (methicillin, } \\
\text { rifampin, allopurinol, phenytoin) [47] }\end{array}$ & No AOP found & & \\
\hline & & $\begin{array}{l}\text { Formation of drug-protein hapten conjugates in renal } \\
\text { tissue which elicit an immunogenic response }\end{array}$ & No AOP found & & \\
\hline
\end{tabular}




\begin{tabular}{|c|c|c|c|c|c|}
\hline & \multirow{2}{*}{$\begin{array}{l}\text { mechanisms } \\
\text { resulting in fibrosis } \\
\text { and renal scarring }\end{array}$} & $\begin{array}{l}\text { (sulfamethoxazole metabolite } \\
\text { nitrososulfamethoxazole, methicillin) [47] }\end{array}$ & & \multirow{2}{*}{$\begin{array}{l}\text { pump inhibitors } \\
\text { (omeprazole); allopurinol, } \\
\text { lithium, aristolochic acid, } \\
\text { phenytoin, propylthiouracil, } \\
\text { ranitidine }[12,25,29,47-49]\end{array}$} & \multirow[t]{2}{*}{$\begin{array}{l}\text { osteopontin }^{\text {VIII) }} \\
{[42,50-52]}\end{array}$} \\
\hline & & (Event 244 (AOP 38):Protein alkylation)** [28] & $\begin{array}{l}\text { (AOP 38: Protein alkylation } \\
\text { leading to liver fibrosis)** [28] }\end{array}$ & & \\
\hline $\begin{array}{l}\text { Tubular } \\
\text { obstruction }\end{array}$ & $\begin{array}{l}\text { Crystal precipitation } \\
\text { within the renal } \\
\text { tubule depending } \\
\text { on urinary } \mathrm{pH} \text { and } \\
\text { favoured by high } \\
\text { concentrations in } \\
\text { the urine }\end{array}$ & $\begin{array}{l}\text { OAT interaction causing secretion via proximal tubule } \\
\text { cells, accumulation and crystal formation in urine } \\
\text { leading to concentration in renal tissue/tubule and } \\
\text { obstructive nephropathy (acyclovir) [37] }\end{array}$ & AOP proposed by Lhasa Ltd. [37] & $\begin{array}{l}\text { antibiotics (e.g. ampicillin, } \\
\text { ciprofloxacin, vancomycin } \\
\text { and sulphonamides), } \\
\text { antivirals (e.g. indinavir and } \\
\text { acyclovir), methotrexate } \\
{[12,37,54]}\end{array}$ & 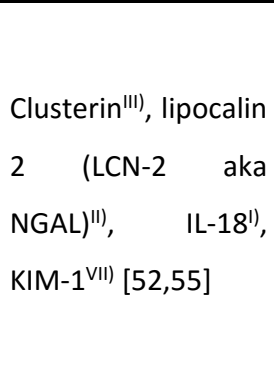 \\
\hline
\end{tabular}


* Interstitial nephritis is not the adverse outcome of these AOPs. However, as NSAIDs have been associated with this mechanism of nephrotoxicity, and KEs, e.g. ROS production and necrosis, are part of this pathway, these AOPs were allocated here.

** This AOP is not directly related to nephrotoxicity but may be relevant for these pathways.

I) IL-18: inflammatory response, activating NFKB in response to ischemia-reperfusion injury of renal tubules (e.g. after contrast agent exposure)

II) LCN-2, NGAL: maximally expressed in kidney after early ischemic injury, in response to contrast agents; important mediator of innate immune responses

III) Clusterin: associated with membrane recycling, cell repair, ischemic injury in proximal and distal tubule

IV) $\quad$ B2-microglobulin: early marker of tubular injury

V) Cystatin C: related to ischemic injury in proximal tubule

VI) Heme oxygenase-1: changes in response to ischemic and cisplatin-induced injury

VII) KIM-1: found in urine after proximal tubular cell injury

VIII) Osteopontin: associated with accumulation of macrophages, expressed in the distal convoluted tubules, the thick ascending limbs of the loop of Henle and the proximal tubule IX) miR-34: was upregulated following cisplatin induced acute kidney injury, may play a cytoprotective role for cell survival Abbreviations:

ACE (angiotensin-converting enzyme) inhibitors; ARBs (angiotensin receptor blockers); 


\subsection{Haemodynamic alteration}

The kidney auto-regulates the pressure within the glomerulus by adjusting the afferent and efferent arterial tone to maintain the glomerular filtration rate (GFR) and urine output [12]. GFR is one of the key parameters to assess intraglomerular haemodynamics as it estimates the volume of blood filtered through the glomeruli per minute [19]. The GFR value considered normal in a healthy adult standardised for a body surface area of $1.73 \mathrm{~m}^{2}-$ is around $100-120 \mathrm{~mL}$ per minute $[19,56]$.

Patients with normal renal function who are being treated for hypertension generally do not encounter an increase in serum creatinine levels [33]. However, patients with chronic renal insufficiency and hypertension do when using antihypertensive drugs. A combination of factors related to chronic hypertension, such as structural and functional changes in small vessels of the kidney, contribute to a decrease in autoregulatory capacity of the renal vasculature leading to a reduced GFR and an increase in serum creatinine concentrations [33].

An excessive lowering of blood pressure through the use of medication may cause a decrease in intraglomerular pressure which may be exacerbated by a decline of efferent arteriole resistance due to vasodilation and/or afferent vasoconstriction $[33,57]$. The use of angiotensin-converting-enzyme (ACE) inhibitors and angiotensin receptor blockers (ARBs) is associated with such effects, in particular with reducing efferent arteriolar tone. However, in patients with chronic kidney disease hypertension is common and a risk factor for the progression of renal damage [58]. Both, ACE inhibitors and ARBs are prescribed for their renoprotective effects in anti-hypertensive therapy, in combination to treat heart failure and CKD with proteinuria [59-62] even though this practice has been debated particularly for CKD patients aged 65 and older $[63,64]$. Also, careful dose titration is judged essential for ACE inhibitors [65] which indicates a narrow therapeutic index. ACE inhibitors prevent the formation of angiotensin II, a potent vasoconstrictor, which acts on vascular smooth muscle cells, with salt- and fluid-retentive properties [32].

Intravascular volume depletion may induce adverse effects of ACE inhibitors on the kidney [33]. ARBs also target the angiotensin II pathway by blocking angiotensin II type 1 (AT1) receptors while not acting on angiotensin II type 2 (AT2) receptors which are stimulated to a higher extent as a result of higher circulating angiotensin II concentrations [33]. AT1 receptors are primarily on efferent vessels increasing vasoconstriction if activated while AT2 receptors are predominantly found on afferent vessels [33,66-68]. AT2 receptor binding has been associated with antagonised renal vasoconstrictor response and natriuresis $[69,70]$. 
Even though ACE inhibitors and ARBs are considered renoprotective administered on their own and to counteract hypertension, they may aggravate nephrotoxic effects in combination with other drugs such as non-steroidal anti-inflammatory drugs (NSAIDs) and diuretics [71]. NSAIDs are known to cause alterations to intraglomerular haemodynamics by inhibiting either one or both isoenzymes of cyclooxygenase (COX-1 and COX-2) and, as a result, suppressing prostaglandin synthesis [24]. Prostaglandins mediate arteriolar vasodilation [72]. In certain conditions of decreased renal perfusion, e.g. cirrhosis and congestive heart failure, or volume depletion, renal function is increasingly dependent on prostaglandins $[72,73]$. In these instances, (selective and non-selective) NSAIDs used at high doses are associated with an increased risk of acute kidney failure [24]. An AOP was proposed describing this pathway [29].

A number of drugs induce renal dysfunction via more than one pathway. In the case of amphotericin $B$ both haemodynamic and tubular adverse effects have been observed. The compound causes vasoconstriction of the renal arteriae, a subsequent decrease in renal blood flow and GFR, and polyuria [74]. On a cellular level, amphotericin B causes modifications in cell membrane integrity and increased influx of $\mathrm{Ca}^{2+}$ into the cytoplasm via newly formed pores [74-76]. These may lead to tubular cell toxicity as further described below.

\subsection{Proximal and distal tubular cell toxicity}

Renal tubular cells, especially proximal tubule cells, are vulnerable to the toxic effects of drugs. This is because their apical and basolateral transport systems facilitate extensive cellular uptake in their function of re-absorbing glomerular filtrate $[20,23]$. Thereby, proximal tubular cells are exposed to a high amount of circulating endogenous and exogenous compounds, including potential nephrotoxicants $[12,20,23]$.

Tubular cell toxicity may be elicited via different pathways which are induced by therapeutic agents such as aminoglycoside antibiotics, cisplatin and amphotericin B $[12,25]$. For instance, aminoglycosides are cationically charged and therefore attracted to the anionic phospholipid-rich brush border located at the proximal tubular apical membrane [76]. Accumulation of the aminoglycosides in tubular cells leads to the disruption of endosomal and lysosomal membrane and activation of intrinsic apoptotic pathway $[45,75,77]$. This includes impaired mitochondrial respiration and induction of oxidative stress through increased free radical levels within the cell. The kidney is particularly vulnerable to reactive oxygen species (ROS) damage [78]. Several nephrotoxic 
compounds, e.g. cisplatin, immunosuppressant drugs, NSAIDS and aminoglycosides, exert their toxic effects due to excess ROS production, and depletion of the antioxidant defence mechanism [78].

Oxidative injury, inflammation, apoptosis, acute tubular necrosis as well as vasoconstriction have been associated with aminoglycosides as well as exposure to cisplatin $[53,75]$. The extent of exposure is suggested to determine whether apoptotic or necrotic cell death is induced. High concentrations of cisplatin in the millimolar range were reported to result in necrosis while concentrations in the micromolar range provoked apoptosis - via the intrinsic mitochondrial, extrinsic death receptor and ER-stress pathways [53].

Experimental data suggested the intrinsic mitochondrial pathway to be the major pathway of cisplatin-induced apoptosis, likely to be induced by sulfhydryl group and mitochondrial glutathione (GSH) depletion [44]. Basolateral uptake by the organic cation transporter OCT2 has been demonstrated to be critical for cisplatin's toxic response to be elicited in the kidney [53]. Also, different segments of the nephron demonstrate diverse sensitivities to cisplatin which did not appear to be due to differences in uptake characteristics but intracellular effects [79]. S1 cells derived from the early portion of the proximal tubule expressed a considerably lower amount of the anti-apoptotic protein $B C L-X_{L}$ than $S 3$ cells derived from the late portion of the proximal tubule and distal convoluted tubular cells [79].

The mitochondria of proximal tubular cells also appear to be key targets of nucleotide and nucleoside antiviral drugs stavudine and cidofovir [37]. Mitochondrial toxicity induced via mitochondrial DNA incorporation or mitochondrial DNA polymerase gamma inhibition may lead to tubular cell necrosis and acute renal failure [37].

Amphotericin B is also commonly associated with acute tubular necrosis which may be secondary to changes in haemodynamics and cell membrane permeability as described above, and resulting renal tubular acidosis and hypokalemia $[74,75,80]$. Unlike aminoglycosides and cisplatin, amphotericin B appears to elicit cellular toxicity predominantly in distal tubular regions as opposed to the proximal tubules $[24,25,53]$.

Another pathway leading to renal tubular necrosis is documented in an AOP related to 4aminophenol exposure whereby 4-aminophenol cysteine S-conjugates reach and get concentrated in 
proximal tubules [36]. There, cysteine S-conjugates are metabolized to benzoquinoneimines which cause oxidative stress and necrotic tubular cell death [36].

\subsection{Tubular, interstitial, tubulo-interstitial and glomerular nephritis}

Certain drugs, e.g. NSAIDs, antibiotics, loop and thiazide diuretics and proton pump inhibitors, induce kidney injury by producing inflammatory changes in the glomerulus, tubular cells and the interstitium, which can lead to fibrosis and renal scarring [12]. Many nephrologists consider these endpoints separately from each other due to differences in mechanisms leading to them. However, NSAID-induced nephritides may not be demarcated from each other but rather indicate a continuous spectrum of renal responses due to hypersensitivity against a drug influenced by the extent of drug exposure [81].

Another study showed that in all forms of progressive glomerulonephritis, a major tubulo-interstitial infiltrate of immune-competent cells was present [82]. Moreover, the outcome of different forms of progressive glomerulonephritis was found to be determined by the presence and severity of tubulointerstitial changes rather than the degree of glomerular alteration [82]. For the purpose of this review, they will be discussed jointly.

Drug-induced acute interstitial nephritis occurs as a result of dose-dependent renal tubular cell damage (including necrosis) or from an immune reaction directed against endogenous antigens in the kidney, and develops in an idiosyncratic, non-dose-dependent fashion $[12,22,47,57,83]$. In immune reaction induced cases, the usual symptoms of hypersensitivity, e.g. fever and rash, may be lacking $[47,83]$. An immunological response may be initiated through the deposition of a drug acting as a hapten or a circulating antibody-drug-based immune complex within the interstitium where it gets targeted by a, mostly cell-mediated, immune response $[47,83]$. As neutrophils and macrophages are attracted to the site, ROS and inflammation mediators are released leading to phagocytosis, tubular cell and glomerular injury $[83,84]$. Common drugs that induce acute interstitial nephritis include allopurinol, NSAIDs, antibiotics, loop and thiazide diuretics and proton pump inhibitors $[12,22,25,75]$.

Chronic interstitial nephritis tends to be less drug-induced, however, has been reported with lithium, NSAIDs and aristolochic acid $[12,20]$. The main characteristics of this mechanism of nephrotoxicity are interstitial fibrosis and interstitial damage by far exceeding any glomerular effects, which may 
include periglomerular fibrosis [22]. Also, tubular atrophy and an inflammatory infiltrate of lymphocytes, plasma cells and macrophages are observed [22].

Glomerulonephritis has been reported to be induced by exposure to gold, interferon- $\alpha$, cephalosporin, penicillin and pamidronate [12]. Its most common cause is IgA nephropathy, which is characterised by deposits of IgA-containing immune complexes in the kidney with proliferation of the glomerular mesangium [85]. Other forms of nephritis may be linked to autoimmune conditions, such as lupus nephritis.

The AOP suggested for aspirin describes the pathway from the MIE of uncoupling/inhibiting mitochondrial oxidative phosphorylation to acute renal failure following acute tubular necrosis [29]. As adverse outcome or KE, interstitial nephritis is not included even though aspirin and other NSAIDs are recognised to induce this endpoint.

\subsection{Tubular obstruction}

Tubular obstruction may be caused through crystal deposition within the renal tubules. Certain drugs such as antibiotics (e.g. ampicillin, ciprofloxacin and sulphonamides), antivirals such as indinavir and acyclovir, light chain antibodies, methotrexate and polyethylene glycol produce insoluble crystals in the body $[12,75,76,86]$. These crystals may precipitate within the distal tubule, and obstruct urine flow. The likelihood of crystal precipitation depends on the amount of drug in the urine, the solubility of the drug and on the $\mathrm{pH}$ of the urine which is altered in conditions of renal tubular acidosis, metabolic acidosis or alkalosis [76,87]. With acidic urine $(\mathrm{pH}<5.5)$, crystal precipitation is increased for sulfonamides and methotrexate, and with alkaline urine $(\mathrm{pH}>6.0)$, it increases for indinavir and ciprofloxacin [76].

Renal hypoperfusion increases the chance of nephrotoxicity through this mechanism as renal tubules are exposed to high drug concentrations for longer than in a normally perfused kidney $[20,87]$. Low perfusion and a high intratubular drug concentration may lead to supersaturation within the distal tubules [88]. If the drug is administered at a high dose, mainly excreted via the kidney in its unchanged form and relatively insoluble in the urine, as in the case of acyclovir, crystal formation and intratubular precipitation is likely to occur [87].

A recent report documented a new mode of cast formation induced by vancomycin [54] which had previously been associated with acute tubular necrosis and acute interstitial nephritis $[12,48,89]$. 
These casts were described as atypical and non-crystalline consisting of vancomycin nanospheres entangled with uromodulin, an abundant protein in normal human urine, present in the tubular lumen and the Bowman's space suggesting tubular obstruction [54].

Little research appears to have been done to understand the formation of different shapes of crystals and their behaviour and pathomechanisms in different parts of the kidney [86].

\subsection{Other mechanisms of nephrotoxicity}

Rhabdomyolysis and thrombotic microangiopathy have been discussed as additional mechanisms of nephrotoxicity elsewhere $[12,57]$ but may also be regarded as systemic causes of nephrotoxicity. Rhabdomyolysis also causes tubular obstruction and refers to a syndrome where disintegration of striated muscle leads to release of muscular cell constituents, predominantly myoglobin and creatinine kinase, into the plasma $[90,91]$. Normally, myoglobin is loosely bound to plasma globulins and only small amounts reach urine. However, in rhabdomyolysis, large amounts of myoglobin are released; significantly more than can be bound by plasma globulins. Myoglobin is then filtered by glomeruli and reaches the tubules, leading to renal obstruction and renal dysfunction [90,91]. Drugs that cause rhabdomyolysis include certain statins, sedative hypnotics and antidepressants, alcohol and agents of abuse such as cocaine, heroin, ketamine, and methadone [90,91]. As nephrotoxicity is not primarily induced by these drugs this pathway is not considered as key mechanism.

Thrombotic microangiopathy (TMA) is predominantly a vascular issue characterised by vessel wall thickening of arterioles or capillaries, and intraluminal platelet thrombosis, which leads to the obstruction of the vessel lumina. If these lesions prevail in the kidney, they are termed haemolytic uremic syndrome (HUS) and they are also, but less frequently, found in thrombotic thrombocytopenic purpura (TTP) which may be more associated with brain lesions [92,93]. Events leading to thrombotic microangiopathy are vascular injury - endothelial cells being the key target -, loss of endothelial thromboresistance, leukocyte adhesion to the damaged endothelium, complement consumption and enhanced vascular shear stress [92]. Drugs that cause nephrotoxicity through thrombotic microangiopathy include mitomycin C, clopidogrel, quinine, cyclosporine and tacrolimus $[25,92,94,95]$. The onset of general clinical manifestations such as microangiopathic haemolytic anaemia, and thrombocytopenia is often delayed [96]. TMA lesions have been reported in about $50 \%$ of 128 patients diagnosed with IgA nephropathy [97], which is tightly linked to glomerulonephritis. 
This, as well as a number of previously mentioned examples (e.g. tubular cell necrosis leading to interstitial nephritis in aspirin-induced nephrotoxicity) show very clearly that some of these mechanisms are interlinked as a number of substances elicit nephrotoxicity via more than one pathway. Mechanistic data describing molecular events initiating these toxicity pathways and effects further down the line are often lacking. Even fewer data are available which help to understand how these may be linked depending on dose and time.

\subsection{Site-Selective Nephrotoxic Injury}

Many drugs selectively cause nephrotoxicity through the above mechanisms on different segments of the nephron.

\subsubsection{Glomerular Injury}

The glomerulus is a primary site of chemical exposure and a number of drugs induce nephrotoxic effects there [74]. Glomerular ultrafiltration may be impaired by compounds acting on endothelial cells causing vasoconstriction of the renal arteriae (i.e. amphotericin B, gentamycin) or substances eliciting direct cytotoxic effect on glomerular epithelial cells (i.e. cyclosporine) [74]. By impairing GFR, the excretion of toxic metabolic waste is diminished. Glomerular injury may also result from circulating immune complexes getting trapped in the glomerulus and attracting neutrophils and macrophages which release ROS [74]. ROS greatly contribute to many glomerular diseases, including glomerulonephritis [98]. Heavy metals (e.g. $\mathrm{HgCl} 2$ ), volatile hydrocarbons and organic solvents cause glomerular injury via the above mechanism, and can also cause an increase in membrane permeability in the glomerulus. This will allow larger molecules e.g. albumin and $\gamma$-globulin, which are normally prevented from entry, to pass to the ultra-filtrate and be excreted along with the urine, thus causing proteinuria $[74,84]$.

\subsubsection{Injury to Tubular Systems}

The most common site of drug-induced renal toxicity is the proximal tubule due to significant accumulation of chemicals in the tubule, contributed by the high reabsorption rates $[74,84]$. The proximal tubular cells have a leaky epithelium, which enhances the flux of compounds into proximal tubular cells, unlike the distant tubule characterised by a tight epithelium with high electrical resistance [74]. The proximal tubules are the critical, if not exclusive, site of transport for organic anions and cations, low-molecular-weight proteins and peptides, GSH conjugates, and heavy metals [74]. Drugs that preferentially affect the proximal tubules include aminoglycosides, $\beta$-lactams 
(including cephalosporins), haloalkane-S-conjugates and $\alpha 2 \mu$-globulin bound chemicals i.e. cadmium, mercury and limonene $[74,84,99]$. For the cephalosporin antibiotic cephaloridine, the correlation between transport, accumulation, and nephrotoxicity is strong but this does not apply to other cephalosporins [74]. The intrinsic reactivity of the compound with molecular or subcellular targets within the proximal tubular cell is considered to be another decisive factor [74]. Chemical-induced injury is less common in the loop of Henle and the distal tubular system compared to the proximal tubules.

\subsubsection{Papillary Injury}

The renal papilla is also targeted for injury, mainly by excessive and abusive use of analgesics (analgesic nephropathy) $[74,100]$. This type of toxicity is characterised by renal papillary necrosis and chronic interstitial nephritis that leads to the onset of progressive kidney failure [100].

\subsection{Bladder Toxicity}

There is limited information on toxicity induced by compounds in the bladder. This could be because urine does not stay there for a long time. However, some carcinogenic compounds are known to target the bladder. One of the earliest examples of bladder cancer due to occupational exposure is 2-napthylamine [74]. Other aromatic amines are also known to be carcinogenic to the bladder. Metabolism of these compounds in the kidney and bladder has been recognised to play a vital role in this toxicity pathway [74]. Similarly, a metabolite of both cytotoxic drugs cyclophosphamide and ifosfamide, i.e. acrolein, is predominantly responsible for urothelial cell toxicity [101-104]. As stable urinary metabolite, acrolein reaches the bladder epithelial lining via the urine where toxicity is believed to be caused by ROS and nitric oxide (NO) production leading to lipid peroxidation, DNA damage and consequently necrotic cell death $[103,104]$. Other bladder related adverse events following drug exposure in humans include urolithiasis, blood in urine, and bladder disorders such as dysuria (i.e. painful urination), urinary incontinence, urinary retention and polyuria [49]. However, these may be additional symptoms of systemic toxicity and not be adverse effects primarily observed in the bladder.

Overall, each of these key mechanisms outlined above includes a number of sub-mechanisms which typically have not been defined conclusively on a molecular or level. An aspect which adds to the level of complexity already encountered when trying to establish models on these (sub-)mechanisms is the fact that some of these (sub-)mechanisms manifest jointly and therefore, appear to be interlinked, e.g. necrosis is part of the tubular cell toxicity mechanism but also appears to be present 
in tubulo-interstitial nephritis. In Table 1, an AOP proposed by Lhasa Ltd. for the nephrotoxicity of NSAIDs is included, which denotes acute tubular necrosis and renal papillary necrosis as post-MIE KEs [29]. NSAIDs have been predominantly associated with interstitial nephritis and hemodynamic alteration $[12,25]$ and not with tubular cell toxicity, which indicates that tubular necrosis is a prestage of interstitial nephritis.

In addition, the sensitivity and specificity of biomarkers, which have been used to a vast extent, e.g. serum creatinine and blood urea nitrogen, have been criticised over the last years $[42,105,106]$. In 2008, the FDA designated seven biomarkers of nephrotoxicity for use in animals and, on a case-bycase basis, in humans. These included urinary KIM-1, $\beta 2$-microglobulin, cystatin $\mathrm{C}$, clusterin, trefoil factor-3, albumin, and total protein. These markers and others (e.g., urinary NGAL, urinary IL-18, and the liver fatty acid binding protein (L-FABP)) have been studied in a range of conditions $[31,39,42,106,107]$. Certain biomarkers, which have been proposed, are specific to particular segments of the nephron but a signal in the proximal tubules may indicate various nephrotoxicity mechanisms. Knowledge is partly available suggesting that they may be attributed to a mechanism of toxicity $[39,42,106]$ but a lot more research is needed to allow for a more refined mechanistic understanding.

\subsection{SOURCES OF DATA / INFORMATION ON KIDNEY TOXICITY SUITABLE FOR COMPUTATIONAL MODELLING}

Physiological, physico-chemical and toxicological data are the bedrock of the development of in silico models for toxicology. Some of the general issues related to data procurement for modelling purposes have been discussed elsewhere [108-113]. If the development of AOPs and multi-scale models is currently considered to be the panacea of $21^{\text {st }}$ century toxicology, data spanning molecular to population levels are necessary to generate multi-scale models resembling the structure of AOPs.

For the registration of many chemicals and pharmaceuticals, adverse effects to the kidney and bladder are currently assessed through traditional toxicological approaches, involving in vitro and in vivo animal studies [114]. However, a standardised test specifically designed to investigate a substance's potential and mechanisms to elicit nephrotoxicity does not exist to date, as this would normally be assessed in repeat dose toxicity testing. In drug development, whilst safety pharmacology studies on the kidney are not part of the core required animal study battery, supplemental studies on the renal and urinary system may be performed if there is cause for 
concern [115]. Furthermore, clinical studies of drug compounds in humans cover endpoints related to renal toxicity but their efficacy to assess this pathology adequately has been challenged by the high number of drug-induced acute renal failure cases in critically ill and chronic kidney disease patients.

A list of over 250 potential nephrotoxicants has been compiled including, where available, information on a putative or confirmed MIE and AOP, using current knowledge from the literature $[12,20,25,28-30,34-39,44-49,53,54,73,86,89,101-104,116-188]$. This list can be accessed via the supplemental information and provides a comprehensive, publicly available compilation of nephrotoxicity data. For modelling purposes, this list needs to be enriched with chemistry-, activityand toxicity-related data. There are over 400 databases available of which over 200 are publicly available geared towards chemistry, toxicology, Absorption, Distribution, Metabolism and Excretion (ADME) properties, as well as molecular biology (-omics) and pathways, which may be accessed for model generation. The following review of databases sheds some light on how well publicly available data may inform future nephrotoxicity modelling. This review is by no means complete but covers the most significant resources currently available for modelling. Searches were performed at timepoints recorded in the references' section.

In reviewing data sources, it must be remembered that several different types of data and data compilations are required and ideally these should be suitable for modelling. Traditional QSAR modelling requires datasets of consistent information for a group of compounds, this could include the presence or absence of nephrotoxicity or quantitative estimates of potency - providing the data have been measured in a consistent manner (i.e. the same test protocol). Read-across can be attempted on smaller data sets - even a one-to-one approach using a potentially wider variety of data - non-standard data from multiple and different sources can be used to build up a weight of evidence. However, physiologically based kinetic (PBK) and multiscale models focus on several parameters (clearance and absorption rates, volume of distribution, partition coefficient) for a single compound. Thus, there may be different uses of the data resources covered in this section.

\subsection{Chemical and biological data}

In order to relate adverse effects to structural components, properties such as solubility, receptor binding, or enzyme inhibition, data on chemical structures, physico-chemical and functional properties and potency are needed. 
A reliable source of information on chemical structures is ChemIDplus Advanced [189, https://chem.nlm.nih.gov/chemidplus/]. A search in the toxicity field for "kidney, ureter, and bladder" effects revealed 139,289 records for 1,352 structures. However, for each record, it is not immediately obvious why a compound is associated with the above mentioned endpoint. ChemIDplus is based on more than 100 sources, including the Comparative Toxicogenomics Database (CTD), the Hazardous Substances Data Bank (HSDB $\left.{ }^{\circledR}\right)$, the Integrated Risk Information System (IRIS), and the International Toxicity Estimates for Risk (ITER) $[190,191]$ such that information - which is often replicated many times, may be drawn from any of these resources.

Other reliable sources of chemical information include, but are not limited to, the following. Chemical structures and physico-chemical properties can be sourced per chemical and downloaded from the U.S. EPA Chemistry Dashboard [192, https://comptox.epa.gov/dashboard/]. Elsewhere, ChEMBL [193,194, https://www.ebi.ac.uk/chembl/] is a database of bioactive compounds which allows access to compound-specific ADME and bioactivity information (e.g. binding measurements, functional assay data) including specifics on the mechanism of action, and (non-)molecular targets. Pharmacological, biological and chemical data of pharmaceuticals and other substances can be found in DrugBank [195,196, https://www.drugbank.ca/]. ChEMBL and DrugBank data may be searched for jointly and in parallel to information from other databases through UniChem $[197,198$, https://www.ebi.ac.uk/unichem/]. Compound-specific physico-chemical properties may also be sourced from PubChem [199,200, https://pubchem.ncbi.nlm.nih.gov/]. The Online Chemical Modelling Environment [201,202, https://ochem.eu/home/show.do] offers pharmacological and physico-chemical data along with an interface for calculating and selecting a number of molecular descriptors.

\subsection{Molecular Biology (-Omics) Data}

High-throughput biology data including genomics, proteomics, transcriptomics and metabolomics in various tissues have been used to identify relevant molecular mechanisms, toxicity pathways, and biomarkers. A number of kidney tissue specific databases discussed below have been established to provide gene, peptide and protein expression data.

The Renal Gene Expression Database (RGED) [203,204, http://rged.wall-eva.net/] and Nephroseq ${ }^{\mathrm{TM}}$ [205, https://www.nephroseq.org/resource/login.html] are platforms providing free access to gene expression information in specific renal diseases. Within RGED, only searches by gene are possible 
while on Nephroseq ${ }^{\mathrm{TM}}$ a more refined analysis may be done on molecular characteristics of disease phenotypes, markers of disease progression and to a very limited extent treatment response.

Data on protein expression in healthy and diseased kidney tissue and urine can be accessed through the Human Kidney \& Urine Proteome Project (HKUPP) [206, http://www.hkupp.org/index.htm]. Search options for data established in the glomerulus, proximal and distal tubules and the collecting ducts from three samples of three kidney cancer patients (two males and one female, aged between 71 and 77) are under construction at the time of this review.

The Urinary Peptidomics and Peak-maps database (UPdb) [207,208, http://www.padb.org/updb/] gathers information on urinary peptides modified in disease. Of relevance to nephrotoxicity modelling are entries related to exposure to mixtures of arsenic and lead [sourced from 209], membranous glomerulonephritis [sourced from 210], IgA nephropathy [sourced from 211] and healthy volunteers as controls [various sources including 212,213].

Via the Kidney \& Urinary Pathway Knowledge Base (KUPKB) [214,215, http://www.kupkb.org/\#tab0], a collection of human and animal derived urine and kidney tissue based miRNA, mRNA, protein and metabolite expression data can be accessed. KUPKB can be searched for information related to specific locations, cells or fluids within the kidney and bladder or a specific condition or disease model. The extent of molecular expression is reported as 'up', 'down', 'present', 'absent', 'medium' and 'strong', which requires accessing the original data source if numerical measures are necessary for further analysis.

Sources of genomics data with a clear focus on toxicity endpoints are the Comparative Toxicogenomics Database (CTD) [216,217, http://ctdbase.org/] and the ToxicoGenomics ProjectGenomics Assisted Toxicity Evaluation system (Open TG-GATEs) [218,219, http://toxico.nibiohn.go.jp/english/]. A search of the CTD for the keyword "kidney" in all sections shows matches with 3 chemicals, 291 genes, 68 gene ontologies, 51 diseases, but 0 pathways. The Open TG-GATEs may be browsed for chemicals or kidney pathologies, which may not be unambiguously assigned to one of the key toxicity mechanisms discussed in more detail below.

\subsection{In vitro}

In vitro data in this section include information from receptor binding and single cell assays up to the sophistication of 3D tissue cultures, bioreactors and organoids. The cheaper and more rapid the 
assay, the greater is the likelihood of a proliferation of data for modelling. A major platform providing high-throughput in vitro screening data is the U.S. Environmental Protection Agency's (EPA) ToxCast ${ }^{\mathrm{TM}}$ programme. On the ToxCast $^{\mathrm{TM}}$ Dashboard website [220, https://actor.epa.gov/dashboard/], when the database was filtered for assays on the kidney, data for 70 assays are shown to be present (according to assay component endpoint names), 1 of which is based on rat kidney membranes, 2 on pig tissues, and 67 on human cell lines. These assays vary to a great extent, for instance in terms of their statistics (e.g. the total number of samples tested, and percent of active samples) or their biological process target (e.g. regulation of catalytic activity, receptor binding, or protein stabilisation). An overview of these assays can be found in Appendix $A$ contained in the supplementary information. When assessing whether a substance is active in an assay, the effect concentrations need to be compared to the compound's burst concentration which denotes a cytotoxic effect at that level [221]. The utility of in vitro ToxCast ${ }^{\mathrm{TM}}$ data has been widely debated [222-229], and a more detailed analysis is required to confirm to which extent these targets are related to currently known KEs of nephrotoxicity pathways. In addition to kidney tissue assays, the ToxCast ${ }^{\mathrm{TM}}$ database contains a broad variety of assays, which may be relevant to in silico models for nephrotoxicity, e.g. cytotoxicity or oxidative stress. Lin and Will [120] found that HepG2 (hepatocellular carcinoma), H9c2 (embryonic myocardium), and NRK-52E (kidney proximal tubule) cells equally serve to screen for general, non-organ-specific cytotoxicity. Therefore, liver, heart or other tissue cells may be suitable for the prediction of nephrotoxicity endpoints.

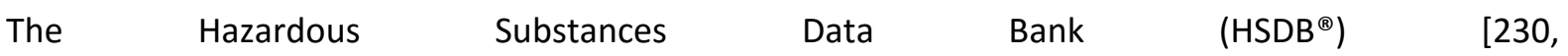
https://toxnet.nlm.nih.gov/newtoxnet/hsdb.htm] contains 393 records for the search term "nephrotoxic*" and 2865 records for "kidney". When selecting "download records", general, i.e. non-nephrotoxicity-specific, in vitro and in vivo animal toxicity, metabolism and pharmacokinetic data may be downloaded as txt file. Renal transporter expression levels, their localisation, substrates and inhibitors may be found on the UCSF-FDA TransPortal [231,232, http://transportal.compbio.ucsf.edu/]. In vitro models of particular interest due to their enhanced complexity and physiological relevance are spheroid and kidney slice assays. Whilst research with spheroids has been conducted to investigate kidney disease and treatment options [233-235], no or few relevant toxicological studies with kidney spheroids were identified. Conversely, toxicity and kinetic studies have been performed in animal and human kidney slices for years [236-239] but no database was identified, in which kidney slice data can specifically be searched for. 


\subsection{In vivo}

In vivo data provide valuable insights into mechanistic pathways of kidney and bladder toxicants and the most meaningful are likely to be gained from long-term, repeated dose, low concentration tests. As with all endpoints, the relevance of inter-species differences must, however, be appreciated if there is an expectation to extrapolate animal data to humans. For instance, amongst many well known issues, rat data cannot be used to establish dose-response relationships of effects dependent on proximal tubular transporter activity as significant differences in transporter clearance between humans and rats exist $[56,240]$.

From the U.S. EPA's Toxicity Reference Database (ToxRefDB), lowest effect levels (LELs) can be retrieved on 30 kidney related toxicity endpoints and 13 urinary bladder related toxicity endpoints [126]. Appendix B contained in the supplementary information lists all these endpoints. However, only 12 compounds were identified with the lowest LEL associated with urinary or kidney endpoints. Other compounds, for which urinary or kidney related LELs were recorded, had LELs associated with other toxicity endpoints lower than those associated with nephrotoxicity.

As mentioned above, in vitro and in vivo animal toxicity, metabolism and pharmacokinetic data may be downloaded in txt file format from the Hazardous Substances Data Bank (HSDB ${ }^{\circledR}$ ). In addition, the COSMOS DB [241,242, http://www.cosmostox.eu/what/COSMOSdb/] contains in vivo toxicity data including highest no effect level (HNEL) and lowest effect level (LEL) information. When performing a database search with a toxicity query for the endpoint "chronic toxicity" and the site "kidney" for all species/strains, routes of exposure, effects, assays and both sexes, 68 hits, i.e. compounds inducing nephrotoxic effects in animals, are presented. For the vast majority of these substances, i.e. 53, one study was recorded; for 13 compounds, 2 studies were recorded and for two substances 4 and 5 studies were presented. A toxicity query for the endpoints "special toxicology study" and "subchronic toxicity" and the site "kidney", resulted in 202 hits with mostly 1 and up to 11 studies recorded. More specific sites can be queried for, e.g. "kidney > renal tubule > epithelial" or "kidney > interstitial cells" which facilitates the search for mechanism-specific toxicity information.

Fraunhofer ITEM created a commercially accessible database on high-quality subacute to chronic toxicity studies called RepDose [243]. A subset of approximately 200 subacute studies is made available for free on http://fraunhofer-repdose.de/ [244]. The database query for "kidney" as organ/target parameter found 113 entries. However, these data were not displayed and query conditions needed to be restricted in order for results to be displayed. After specifying the effect 
"nephropathy", 8 entries were found and displayed, i.e. the CAS numbers and names of 8 substances. 9 entries were identified for "kidney" and "necrosis". These results indicate that RepDose may be used to identify potential nephrotoxicants but does not provide in vivo data for further analysis.

A Urinary Protein Biomarker (UPB) database in Chinese language may be accessed via http://bmicc.cn/web/share/search/hupd [245].

\subsection{Human data - clinical and post-marketing}

For known nephrotoxicants, clinical and post-marketing data as well as case reports in the public domain give insight into toxic effects observed in humans at a given dose. Most valuable are clinical data as doses and effects are clearly recorded. With the use of more refined biomarkers, more information will be gained from these studies in the future.

From the Hazardous Substances Data Bank $\left(\mathrm{HSDB}^{\circledR}\right)$, epidemiological data and case reports can be retrieved in the form of a txt file. However, data gathered from post-marketing reports often do not include (reliable) information on the dose taken by the patient. If dosing information is available - as in the case of clinical studies -, it may be challenging to compare dose-response data of investigations which adhered to differing classifications as different definitions and criteria to classify the severity of certain nephropathy outcomes exist [24].

The U.S. National Library of Medicine provides clinical trial data on ClinicalTrials.gov [246, https://clinicaltrials.gov/]. Queries can be performed for substances, however, not for adverse events. Dosing information and adverse events are published for completed studies but these data do not appear in the downloadable record.

The U.S. Food and Drug Administration (FDA) Adverse Event Reporting System (FAERS), formerly AERS, can be accessed via http://www.fdable.com/basic query/aers [247] and was searched for kidney related specific event descriptions such as kidney fibrosis or focal glomerulonephritis, or renal failure in general. Among the information given are the primary suspect drug, patient outcome, age and gender of the patient. Adverse event data existing in FAERS may have been submitted to the FDA by drug and therapeutic biological product manufacturers, healthcare professionals or consumers. When using these data, their limitations need to be taken into account, i.e. no proof of a causal relationship between exposure to a drug and adverse event, duplicate reports and inherent 
incompleteness of the database [248]. Ursem et al. [49] grouped adverse effects reported to FDA's previously established Spontaneous Reporting System (SRS) and the AERS into a renal disorder cluster, a nephropathies cluster, a kidney function tests cluster and a bladder disorder cluster and through a weight of evidence approach identified substances most likely to induce these cluster endpoints.

When accessing EudraVigilance, the European database of suspected adverse drug reaction reports [249, http://www.adrreports.eu/], the number of individual cases of adverse events following the administration of a drug can be queried. Searches are performed for drug products or substances, and occurrences on "Renal and urinary disorders" per age group may be retrieved on the section "Number of Individual Cases by Reaction Groups". Displayed graphs clearly show whether renal and urinary disorders are predominant adverse events for a particular drug but no information are immediately evident on comorbidities of the patient population and exact doses administered.

\subsection{Relevance of existing sources to in silico modelling}

Section 3 demonstrates considerable resources for in silico modelling of nephrotoxicity. However, no comprehensive database exists with multi-scale information that can be used for in silico nephrotoxicity model development. Databases focussing on kidney tissue data (predominantly in the omics field) are principally geared towards the diagnostics, understanding pathological pathways and treatment of kidney disease as opposed to chemical induced kidney toxicity. In order to establish reliable dose-response relationships, in vivo data are highly desirable. The AOP paradigm and means of organising information provides a possible structure to multi-scale models. Table 2 summarises which type of data informs the various parts of an AOP-structured multi-scale in silico model. The use of (novel and existing) data sources to support in silico modelling is taken up in more detail in Section 5 (Expert Opinion).

Table 2: Data informing all stages of a multi-scale in silico model

\begin{tabular}{|l|l|l|l|l|}
\hline Level & Mechanism & Cellular & Apical toxicity & Human toxicity \\
\hline Examples of & Molecular biology & In vitro data on & In vivo data on & Clinical trials / \\
data and what & (-omics) data on & receptor binding, & mechanistic & post-marketing \\
they may be & MIEs or, if & cellular toxicity, & pathways and & data on human- \\
used for & unavailable, other & cellular uptake, & their association & specific effects, \\
& molecular & enzymatic & with biomarkers & dose-response- \\
& mechanisms & activity & & relationships, \\
\hline
\end{tabular}




\begin{tabular}{|l|l|l|l|l|}
\hline & & & & $\begin{array}{l}\text { sensitivity/ } \\
\text { specificity of } \\
\text { biomarkers }\end{array}$ \\
\hline $\begin{array}{l}\text { Comparative } \\
\text { databases }\end{array}$ & $\begin{array}{l}\text { RGED, } \\
\text { Nephroseq }\end{array}$ \\
& $\begin{array}{l}\text { TMUPP, } \\
\text { KUPKB, CTD }\end{array}$ & $\begin{array}{l}\text { ToxCast }^{\text {TM }}, \\
\text { HSDB }^{\circledR}, \quad \text { UCSF- } \\
\text { KDA TransPortal }\end{array}$ & $\begin{array}{l}\text { ToxRefDB, } \\
\text { COSMOS DB, } \\
\text { RepDose, UPB }\end{array}$ & $\begin{array}{l}\text { HSDB }^{\circledR}, \\
\text { ClinicalTrials.gov, } \\
\text { FAERS, } \\
\text { EudraVigilance }\end{array}$ \\
\hline
\end{tabular}

\section{0 (Q)SARS AND MATHEMATICAL MODELS TO SIMULATE KINETICS AND TOXICITY: CURRENT STATE-OF-THE-ART AND NEXT STEPS}

As noted above, as part of the hazard identification process it is important to be able to predict accurately human nephrotoxicity. The traditional approach for determining safety and toxicity of drug candidates is through histopathological observation from in vivo animal studies [42,250-252] or, more recently, from targeted in vitro testing. However, in recent decades, alternative methods for hazard assessment without the need for testing, such as in silico approaches, have been increasingly applied, particularly for the prioritisation of data requirements and identification of chemicals that may require more detailed risk assessment. Computational toxicology also allows for the possibility to link molecular pathways to cellular processes and a toxicity endpoint at the tissue level.

In this review, two fundamentally different in silico toxicology methods are discussed, i.e. chemistry driven (Q)SARs and physiologically-based mathematical models. The former identify relationships between a structure of a molecule and its toxicity while the latter simulate the physiologically-based toxicokinetics of a compound which allows predictions of whether (and which) effects may be elicited.

\section{1 (Q)SAR models}

In silico methods include chemical structure driven SARs and physico-chemical property and molecular descriptor driven QSARs to predict and profile toxicities [253]. These provide a correlation between an effect, often a regulatory endpoint, and properties of a molecule. SARs are often developed into SAs which relate qualitatively a particular biological effect or toxicity endpoint to a specific fragment of a molecule $[253,254]$. SAs have been developed to aid identification of 
chemicals that can bind to proteins $[255,256]$ or induce mitochondrial toxicity [257]. These chemicalbiological interactions have been identified as potential mechanisms of eliciting renal (and other) toxicities. SAs associated with potential toxicity have been compiled and encoded into predictive software, for example ToxAlerts - a freely available screening tool available within the online chemical modelling environment (https://ochem.eu/home/show.do) and the alerts incorporated in DEREK Nexus (Lhasa Ltd, Leeds). For certain compounds, toxicity may be elicited via the formation of reactive metabolites, rather than inherent toxicity of the parent molecule. Claesson and Minidis [258] have collated and organised publicly available SAs that may be associated with reactive metabolite formation and idiosyncratic adverse drug reactions. QSARs provide a statistical relationship between the structure of a chemical, its physico-chemical properties and its effects [253]. QSAR models have demonstrated good predictive ability, especially for simple end points $[250,259]$.

The primary objective of (Q)SARs is to distinguish between toxicologically inactive or active compounds and, where possible, provide a quantitative estimate of potency or relative effect. Frequently, several mechanisms elicit the same toxicological endpoint. Thus, predictive models must be able to distinguish all fragments corresponding to all relevant mechanisms from inactive fragments. Two main types of commercial systems have been developed: knowledge-based systems (e.g, DEREK Nexus and OncoLogic) and statistically-based systems (e.g. TOPKAT and MultiCASE) [260] although there is a trend for hybrid systems which may link a quantitative estimate to an SA e.g. ChemTunes [261, https://www.mn-am.com/products/chemtunes]. Knowledge-based systems use rules derived from human expert opinion and interpretation of toxicology data to define the relationship between a structure and its activity. These rules are utilised to predict potential toxicity of known and novel chemical compounds. Statistically-based systems use calculated parameters and statistical methods to derive mathematical relationships for a training set of compounds [260].

(Q)SAR models developed so far for nephrotoxicity, specifically, are summarised in Table 3 with details on the exact endpoint, number and type of molecules the model is based on, the method used, results, as well as strengths and weaknesses of the approach below. 
Table 3: Summary of (Q)SAR models associated with kidney and bladder toxicity

\begin{tabular}{|c|c|c|c|c|c|c|}
\hline Endpoint & $\begin{array}{l}\text { Number and type } \\
\text { of molecules }\end{array}$ & Method & Results: QSAR / SAR & Strengths & Weaknesses & $\begin{array}{l}\text { Model } \\
\text { reference }\end{array}$ \\
\hline Rat nephrotoxicity & $\begin{array}{l}16 \text { derivatives or } \\
1,2-\text { and } 1,4- \\
\text { naphthoquinones }\end{array}$ & SA & $\begin{array}{l}\text { Whilst preliminary SAs were } \\
\text { presented, no definitive SAs } \\
\text { were defined }\end{array}$ & $\begin{array}{l}\text { Changes in the extent of } \\
\text { nephrotoxicity due to structural } \\
\text { alterations of 2-hydroxy-1,4- } \\
\text { naphthoquinone and 4-amino-1,2,- } \\
\text { naphthoquinone were determined }\end{array}$ & $\begin{array}{l}\text { No SAs identified; mechanism of } \\
\text { toxicity was not determined, small } \\
\text { applicability domain }\end{array}$ & $\begin{array}{l}\text { Munday } \\
\text { et al. } \\
\text { [262] }\end{array}$ \\
\hline $\begin{array}{l}\text { Toxicity to the kidney } \\
\text { and urinary tract based } \\
\text { on repeat-dose toxicity } \\
\text { study-derived NOAELs } \\
\text { and LOAELs in rats }\end{array}$ & 503 chemicals & $\begin{array}{l}\text { SAs based on } \\
\text { likelihood ratio } \\
\text { and percentage } \\
\text { of true positives }\end{array}$ & $6 \mathrm{SAs}$ & $\begin{array}{l}\text { Mechanistic information available } \\
\text { for some SAs based on literature }\end{array}$ & $\begin{array}{l}\text { Mode of action data is generally } \\
\text { basic and not available for all SAs }\end{array}$ & $\begin{array}{l}\text { Pizzo et } \\
\text { al. [263] }\end{array}$ \\
\hline Nephrotoxicity & $\begin{array}{l}\text { Confidential } \\
\text { database } \\
\text { amalgamated from } \\
\text { multiple industries }\end{array}$ & $\begin{array}{l}\text { Knowledge-based } \\
\text { expert system } \\
\text { using SARs }\end{array}$ & SAs & $\begin{array}{l}\text { SAs are in some cases associated } \\
\text { with mechanistic information }\end{array}$ & $\begin{array}{l}\text { Certain substances, e.g. inorganic } \\
\text { compounds, cannot be analysed }\end{array}$ & $\begin{array}{l}\text { Derek } \\
\text { Nexus } \\
{[264]}\end{array}$ \\
\hline $\begin{array}{l}\text { "Nephrotoxicity" } \\
\text { and } \\
\text { endpoints } \\
\text { necrosis" } \text { (KN), "kidney } \\
\text { relative weight gain" } \\
\text { (KWG) and "nephron } \\
\text { injury" (NI) }\end{array}$ & $\begin{array}{l}\text { Training set: } \\
\text { NT: 847; KN: 221; } \\
\text { KWG: 240; NI: 598; } \\
\text { Test set: } \\
\text { NT: 154; KN: 42; } \\
\text { KWG: 49; NI: } 109\end{array}$ & $\begin{array}{l}\text { QSAR models and } \\
\text { toxicophores }\end{array}$ & $\begin{array}{l}192 \text { SAs for all kidney- } \\
\text { related endpoints }\end{array}$ & $\begin{array}{l}\text { QSAR models demonstrate good } \\
\text { performance overall; QSARs and } \\
\text { toxicophores were based on the } \\
\text { same compound sets; } \\
\text { comparatively broad applicability } \\
\text { domain }\end{array}$ & $\begin{array}{l}\text { Endpoints "kidney weight gain", } \\
\text { "nephron injury" and } \\
\text { "nephrotoxicity" cannot be } \\
\text { specifically attributed to a } \\
\text { nephrotoxicity mechanism }\end{array}$ & $\begin{array}{l}\text { Myshkin } \\
\text { et al. } \\
\text { [265] }\end{array}$ \\
\hline $\begin{array}{l}\text { Competency of rat liver } \\
\text { MGST1 to catalyse }\end{array}$ & $\begin{array}{l}9 \text { haloalkenes; as } \\
\text { no or low GSH }\end{array}$ & QSAR model & $\begin{array}{l}\text { Linear relationship between } \\
E_{\text {LUmo }} \text { values between }-1.14\end{array}$ & $\begin{array}{l}\text { Findings may be valuable for } \\
\text { understanding and predicting the }\end{array}$ & $\begin{array}{l}\text { Small applicability domain; linear } \\
\text { relationship does not exist for }\end{array}$ & $\begin{array}{l}\text { Jolivette } \\
\text { and }\end{array}$ \\
\hline
\end{tabular}




\begin{tabular}{|c|c|c|c|c|c|c|}
\hline $\begin{array}{l}\text { bioactivation of } \\
\text { molecules to toxic } \\
\text { metabolites }\end{array}$ & $\begin{array}{l}\text { transferase activity } \\
\text { was detected for } 4 \\
\text { molecules, QSAR } \\
\text { was investigated } \\
\text { for } 5 \text { haloalkenes }\end{array}$ & & $\begin{array}{l}\text { to }-0.73 \mathrm{eV} \text { and the natural } \\
\text { logarithms of activities for } \\
\text { GSH conjugation reaction }\end{array}$ & $\begin{array}{l}\text { route of metabolism of } \\
\text { haloalkenes and their associated } \\
\text { toxicities; haloalkenes are widely } \\
\text { used, so results may help to make } \\
\text { chemical design amendments for } \\
\text { many applications }\end{array}$ & $\begin{array}{l}\text { ELUMO values outside of }-1.14 \text { to }- \\
0.73 \mathrm{eV} \text { range }\end{array}$ & $\begin{array}{l}\text { Anders } \\
{[266]}\end{array}$ \\
\hline $\begin{array}{l}\alpha 2 \mu \text {-globulin } \\
\text { nephropathy in male rats }\end{array}$ & $\begin{array}{lr}\text { Not specifically } \\
\text { known, dataset } \\
\text { includes } 43 \quad 43 \\
\text { aliphatic } & \text { and } \\
\text { alicyclic } & \\
\text { hydrocarbon } & \\
\text { structures } & \end{array}$ & $\begin{array}{l}\text { Combination of } \\
\text { two QSARs based } \\
\text { on multiple } \\
\text { regression } \\
\text { analysis and } \\
\text { principal } \\
\text { component } \\
\text { analysis }\end{array}$ & $\begin{array}{l}\text { Incorporating electro- } \\
\text { negativity properties, size } \\
\text { and shape dependent fit of } \\
\text { binding site: } \log I \mathrm{C}_{50}=4.525 \\
\text { (-ve charge density) }-0.044 \\
\text { (Mol Vol) = 2.545; } r_{2}= \\
0.836 ; \text { cross-validated } r_{2}= \\
0.601\end{array}$ & $\begin{array}{l}\text { To identify whether kidney lesions } \\
\text { observed in in vivo studies in male } \\
\text { rats may be caused by this } \\
\text { pathway }\end{array}$ & $\begin{array}{l}\text { Mechanism specific to male rats, not } \\
\text { relevant to humans; applicability } \\
\text { domain was not discussed }\end{array}$ & $\begin{array}{l}\text { Barratt } \\
{[99]}\end{array}$ \\
\hline $\begin{array}{l}\text { Tubular necrosis, } \\
\text { interstitial nephritis and } \\
\text { tubulo-interstitial } \\
\text { nephritis in humans }\end{array}$ & $\begin{array}{l}\text { Parent compounds } \\
\text { (251 } \\
\text { nephrotoxicants } \\
\text { and } 387 \text { non- } \\
\text { nephrotoxicants) } \\
\text { and their urinary } \\
\text { metabolites (307 } \\
\text { nephrotoxicants } \\
\text { and } 233 \text { non- } \\
\text { nephrotoxicants) }\end{array}$ & $\begin{array}{l}\text { Binary } \\
\text { classification } \\
\text { QSAR models }\end{array}$ & $\begin{array}{l}\text { Eight substructure } \\
\text { fragments common to both } \\
\text { datasets for all of the above } \\
\text { three nephrotoxicity } \\
\text { mechanisms }\end{array}$ & $\begin{array}{l}\text { Metabolism-dependent toxicity; } \\
\text { may help to understand to which } \\
\text { extent and how the three } \\
\text { mechanisms are interlinked; } \\
\text { consideration of metabolites; } \\
\text { based on human data }\end{array}$ & $\begin{array}{l}\text { Model could not be accessed; data } \\
\text { on molecules were not published }\end{array}$ & $\begin{array}{l}\text { Lee et al. } \\
\text { [252] }\end{array}$ \\
\hline $\begin{array}{l}\text { "Nephropathies", "acute } \\
\text { renal disorders", } \\
\text { "bladder disorders", }\end{array}$ & $\begin{array}{l}\text { Not specifically } \\
\text { known }\end{array}$ & QSAR models & $\begin{array}{l}\text { Four QSAR programmes } \\
\text { were used, i.e. MC4PC, } \\
\text { BioEpisteme, MDL QSAR }\end{array}$ & $\begin{array}{l}\text { Based on human data and four } \\
\text { QSAR programmes with different } \\
\text { prediction programmes; high }\end{array}$ & $\begin{array}{l}\text { Non-uniform reporting of adverse } \\
\text { events post marketing approval; } \\
\text { patient population with multi-drug }\end{array}$ & $\begin{array}{l}\text { Matthews } \\
\text { et al. } \\
\text { [267] }\end{array}$ \\
\hline
\end{tabular}




\begin{tabular}{|c|c|c|c|c|c|c|}
\hline $\begin{array}{l}\text { "blood in urine", } \\
\text { "urolithiases" and } \\
\text { "kidney function tests" in } \\
\text { humans }\end{array}$ & & & $\begin{array}{l}\text { and Leadscope Predictive } \\
\text { Data Miner }\end{array}$ & $\begin{array}{l}\text { applicability domain among } \\
\text { pharmaceuticals }\end{array}$ & $\begin{array}{l}\text { exposure and co-morbidities; certain } \\
\text { drugs (inorganic chemicals, high } \\
\text { molecular weight substances (>5000 } \\
\text { Da), organometallic chemicals, gases) } \\
\text { and industrial chemicals not covered; } \\
\text { while specificity was set at }>80 \% \text {, } \\
\text { sensitivity was in some cases very } \\
\text { low }(<20 \%)\end{array}$ & \\
\hline $\begin{array}{l}\text { Pathways associated } \\
\text { with renal tubular } \\
\text { degeneration based on } \\
\text { rat kidney data }\end{array}$ & $\begin{array}{l}88 \text { chemicals, } \\
\text { including } 22 \\
\text { molecules inducing } \\
\text { renal tubular } \\
\text { degeneration }\end{array}$ & $\begin{array}{l}\text { QSAR linking } \\
\text { physico-chemical } \\
\text { features to } \\
\text { transcriptional } \\
\text { activity }\end{array}$ & $\begin{array}{l}\text { Nephrotoxic substances are } \\
\text { associated with high } \\
\text { polarisability, low } \\
\text { electronegativity, and low } \\
\text { symmetry }\end{array}$ & $\begin{array}{l}\text { Multi-scale modelling linking } \\
\text { chemical data to gene expression } \\
\text { and a nephropathological outcome }\end{array}$ & $\begin{array}{l}\text { Focus on agents which directly act } \\
\text { on proximal tubular cells; } \\
\text { applicability domain is unclear }\end{array}$ & $\begin{array}{l}\text { Antczak } \\
\text { et al. } \\
\text { [268] }\end{array}$ \\
\hline $\begin{array}{l}\text { Renal adverse drug } \\
\text { reactions }\end{array}$ & $\begin{array}{l}507 \text { drugs (126 } \\
\text { active, } 208 \\
\text { inactive, } 173 \text { of } \\
\text { undetermined } \\
\text { activity) }\end{array}$ & $\begin{array}{l}\text { QSAR based on } \\
\text { decision tree } \\
\text { inference analysis } \\
\text { using CART and } \\
\text { CHAID }\end{array}$ & $\begin{array}{l}\text { CART model highlights } \\
\text { influence of amine } \\
\text { functions, sulphur, and } \\
\text { carboaromatic ring } \\
\text { structures. For substances } \\
\text { less toxic to the kidney, } \\
\text { CHAID model found few } \\
\text { aromatic atoms (<19), a } \\
\text { basic pKa }<10.71, \text { van der } \\
\text { Waals surface area }<1,014.5 \\
\AA^{2} \text {, and logP values }>2.43\end{array}$ & $\begin{array}{l}\text { Both models performed well, with } \\
\text { CART and CHAID model CCRs of } \\
88.6 \text { and } 84.7 \% \text {, respectively; } \\
\text { based on human data }\end{array}$ & $\begin{array}{l}\text { Only valid for drug-like molecules, } \\
\text { not necessarily suitable for other } \\
\text { compounds }\end{array}$ & $\begin{array}{l}\text { Hammann } \\
\text { et al. } \\
\text { [269] }\end{array}$ \\
\hline $\begin{array}{l}\text { Urinary tract toxicity } \\
\left(\mathrm{LD}_{50} \text { in kidney, ureter, }\right.\end{array}$ & $\begin{array}{l}258 \text { organic } \\
\text { compounds }\end{array}$ & $\begin{array}{l}\text { Classification and } \\
\text { regression QSAR } \\
\text { models based on }\end{array}$ & $\begin{array}{l}\text { SVMBoost based on the RBF } \\
\text { kernel accomplishes the } \\
\text { best quantitative and }\end{array}$ & $\begin{array}{l}\text { Reliable prediction is achieved by } \\
\text { both regression and classification }\end{array}$ & $\begin{array}{l}\text { Adequacy of mouse intraperitoneal } \\
\mathrm{LD}_{50} \text { values as endpoint is unclear }\end{array}$ & $\begin{array}{l}\text { Lei et al. } \\
\text { [270] }\end{array}$ \\
\hline
\end{tabular}




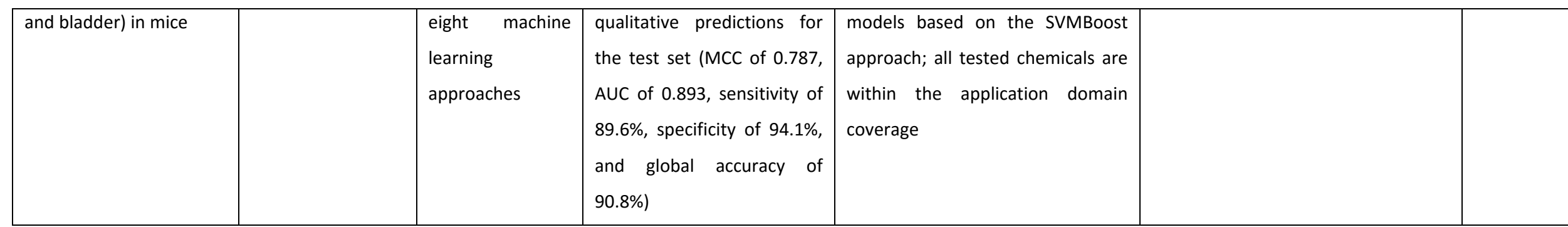

Abbreviations: $\mathrm{CART}=$ classification and regression tree; $\mathrm{CHAID}=$ chi-squared automatic interaction detector; $C \mathrm{CRs}=$ corrected classification rates; $\mathrm{LD}_{50}=$ dose which is lethal to half of total treated animals 
More detailed information on these QSAR models are provided in Appendix C [87,99,252,262-276] of the supplementary information. It is also noted that QSAR models have been developed to predict renal clearance, which were examined in more detail elsewhere [56].

\subsection{Mathematical (mechanism-based) models}

In contrast to (Q)SAR methods, mathematical mechanistic and physiologically-based models can be used to simulate the kinetics of a compound through the body and at the site of toxicity. As a vast number and quantity of substances are moving through the kidney, and considering the key principle of toxicology - the dose makes the poison (Paracelsus) - an understanding of a compound's movement and its potential for accumulation at specific sections of the kidney are considered critical. In section 2, accumulation is described to play an important role in certain nephrotoxicity pathways.

Some of the early mechanistic models to predict renal clearance include passive reabsorption and urine flow [277], which are supplemented by protein binding and glomerular filtration [278-281] and active secretion [282-285]. Subsequently, Felmlee et al. [286] develop a hybrid physiological, mechanistic toxicokinetic (TK) model to simulate the saturable renal reabsorption and capacitylimited metabolic clearance of $\gamma$-hydroxybutyric acid (GHB) with two ultrafiltrate compartments representing the proximal and distal tubules, and active renal reabsorption from the first ultrafiltrate compartment only. Two (fast and slow) tissue distribution compartments best described plasma GHB concentration. As in earlier models, urine flow and the glomerular filtration rate (GFR) are included, while passive reabsorption, active secretion and protein binding are not incorporated, as they do not seem to play a vital role in the renal elimination of GHB.

Felmlee et al. [287] extended their work by adding active tubular secretion to their investigations into active tubular reabsorption. The authors evaluate previously published compartmental and semi-physiologically based models pharmacokinetic (PK) models of active tubular reabsorption and secretion. By merging some of these approaches, they establish a universal mechanistic model predicting renal clearance of substances being subject to active secretion, active reabsorption or both of these processes, for a broad applicability domain. Metabolism and passive reabsorption are not considered in this study. 
Independent of models to predict the kinetics of therapeutic or other chemical compounds, Layton [288] review mathematical models to describe physiological and pathophysiological processes of the kidney. These processes include the regulation of glomerular filtration and renal blood flow by the tubulo-glomerular feedback and myogenic mechanism, epithelial and renal oxygen transport, and the urine concentrating mechanism. A mechanistic understanding of intrarenal oxygen transport and consumption may be a valuable component to add to a toxicokinetics related kidney model as renal tissue hypoxia has been argued to drive kidney disease $[289,290]$.

One of the most detailed mechanistic kidney models is Mech KiM which predicts renal elimination by accounting for glomerular filtration, active and passive reabsorption, active and passive secretion, renal metabolism, bypass of parts of the renal blood flow, transporter scaling factors and population variability [56]. The nephron is divided into eight segments representing the glomerulus, proximal and distal tubules, Loop of Henle and collecting ducts. Each segment encompasses three compartments, illustrating the blood space, tubular fluid and cellular mass. While applying the law of conservation of mass, ordinary differential equations describe the movement of a compound between compartments. Limitations of this model revolve around missing data, e.g. on proximal tubular cells per gram of kidney (PTCPGK) and absolute renal transporter abundances at different parts of the nephron.

Overall, there are limited computational toxicity methods available for more complex endpoints such as nephrotoxicity - likely to be due to the highly complex mechanisms of toxicity $[250,252,262]$ or limitations of the availability of structured, high quality data. Most models presented above focus only on very small groups of compounds, meaning that the applicability domain is limited to the specific groups of compounds used to develop the model. Some models, i.e. Lee et al. [252], Myshkin et al. [265], Matthews et al. [267] and DEREK, have been generated on the basis of larger datasets or commercial software which are not publicly available. Mechanistic models to compute the biokinetics of compounds have limitations due to missing data and are in part not publically available either. To date, there is no multi-scale nephrotoxicity model available which may be due to the lack of high quality data connecting molecular and cellular mechanisms to tissue and organ processes leading to an adverse individual outcome while understanding uncertainties related to inter-individual variability. In the following section, knowledge of the main mechanisms of nephrotoxicity as well as missing information vital to modelling purposes will be summarised. 


\subsection{EXPERT OPINION}

As a major organ of elimination and therefore subject to high exposure of compounds, the kidney has been recognised as a significant target for drug and chemical induced toxicity. This, and the lack of comprehensive test data for many chemicals in sectors other than pharma, clearly show that screening for, and assessment of, nephrotoxicity is an important area for improvement. In silico methods have been evolving steadily and have the potential to contribute immensely to the field of toxicology in general. Although several in silico models currently exist for other organ-level toxicities e.g. hepatotoxicity, this review has found that in silico models associated with nephrotoxicity are very limited, and even fewer differentiate between key mechanisms or incorporate mechanistic data.

In order to improve and expedite the development of in silico models for kidney toxicity, at least three - highly interrelated - problems have to be overcome. These are:

i) The identification and definition of effects to the kidney that may be brought about by chemical exposure.

ii) A full description of relevant mechanisms of toxic action relevant to kidney toxicity.

iii) Access to appropriate data ranging from in vivo through to molecular responses.

The identification of effects to the kidney requires an ontology to be developed that will unify existing knowledge. This may grow out of networked AOPs although would benefit from a systematic evaluation of current knowledge and effects. Once an ontology has been developed it would be the ideal starting point for a framework to underpin data and models. With regard to the data from which to develop the models, no assay exists which is specifically targeted towards renal toxicity endpoints and interspecies variability between rats and humans is known to be relevant for certain pathways (i.e. certain transporter-driven and $\alpha 2 \mu$-globulin related nephrotoxicity). Therefore, the usefulness of in vivo data in the area needs to be assessed carefully. Human and in vitro assay data are widely available but need to be utilised with care due to challenges related to relevance for one of the discussed nephrotoxicity mechanisms, comparability of studies, pre-existing comorbidities in patient populations and other factors related to data interpretation. A strategic for utilising existing data at different levels of AOPs is shown in Table 2. Such an approach to organising information, as defined within an appropriate ontology, may prove to be an extremely effective, and not requiring full testing of every compound, solution to model development. In addition, as the lack 
of readily available data is considered to be a key limiting factor when it comes to the generation of future computational models in this field, therefore the following recommendations may help to drive future modelling efforts forward:

(i) Improved understanding of how novel, recently proposed, biomarkers relate to the mechanisms of nephrotoxicity, discussed earlier, and how they are related quantitatively to each other. This may result in alternative sources of data and could be facilitated by statistical approaches.

(ii) A global review of the quality of currently available kidney toxicity data is needed as well as an assessment of how these data relate to each other (e.g. cellular vs. tissue vs. organ-level effects). Information would be leveraged more readily if databases allowed for searches on both compounds and mechanistic data (including dosing information) enabling discrimination between the various nephrotoxicity endpoints.

(iii) Generation of more AOPs for nephrotoxicity with MIE and KE related data being searchable in a central database linked to respective mechanistic toxicological data would also assist the development of more computational models.

The linkages between in silico models have been defined clearly, with data related to the MIE being able to contribute to the development of a model [10]. While a binary interpretation of an MIE may be used to understand whether a substance has the potential to elicit such a molecular event, a more quantitative understanding of MIEs and KEs may also be achieved with predictive models [291]. For this, potency measurements, i.e. dose response relationships, of substances inducing MIEs and biological events further down the pathway are necessary in order to establish the relationship between these biological events [291]. Once more nephrotoxicity-related AOPs have been developed, an AOP-derived in silico framework would provide the robustness needed for a model to reliably inform screening of new drug candidates, and efforts to prioritise substances for further testing.

With regard to developing better in silico modelling frameworks it is the development of SAs which is the logical starting point. These need to be refined and extended in order to facilitate the prediction of the hazard potential of a more comprehensive array of compounds. For instance, much existing knowledge on SAs has been compiled [292]. The existing knowledge needs to be rationalised such that a robust set of SAs can be established. Such an "in silico profiler" will assist in the designing-out of toxicity as well as grouping, allowing for read-across, especially to estimate the chronic toxicity of data-poor substances. A potentially rich source of information to develop further structural information are the data resultant from ToxCast. It has been shown that fingerprints using 
available ToxCast data on kidney tissue cell lines may be developed [293]. Such fingerprints could consist of a defined number of in vitro assays reflecting the toxic mechanism of a specific group of known nephrotoxicants. If a new chemical is shown to generate hits according to one of the defined fingerprints, the likelihood of the chemical to cause nephrotoxic effects is considered to be high.

Of the in silico models developed so far, there is always a place for QSARs, but only where suitable data allow. These may be based, for instance, around in vitro data for specific effects as opposed to the more ambitious modelling of whole organism toxicity. To facilitate better QSARs, besides incorporating data related to the toxicodynamics of a compound in the kidney, accounting for toxicokinetics and the potential of a substance to accumulate at a specific site within the kidney is considered to be equally important as an adverse effect may be caused due to supersaturation of parts of renal system. In vitro analyses indicate that many chemicals elicit toxicity via unspecific cytotoxicity [223,225,294]. Therefore, a mechanistic model simulating the toxicokinetics of compounds in the different parts of a nephron would help to understand whether a substance may be accumulating or not. Overall, it is clear that experimental and computational efforts have to go hand in hand, along with development of mechanistic knowledge, to achieve much-needed progress in this area.

\section{Methods:}

The scientific literature available via Google Scholar, ScienceDirect, PubMed, Web of Science and Scopus was reviewed for nephrotoxic substances, information related to mechanisms of nephrotoxicity and existing computational models to predict nephrotoxicity. Nephrotoxicants and mechanistic data were identified by searching the terms "drug-induced nephrotoxicity" OR "druginduced kidney toxicity" OR "drug-induced kidney injury" OR "drug-induced kidney damage" OR "drug-induced urinary tract toxicity", and "chemical-induced nephrotoxicity" OR "chemical-induced kidney toxicity" OR "chemical-induced kidney injury" OR "chemical-induced kidney damage" OR "chemical-induced urinary tract toxicity". Nephrotoxicants were also identified from the combined COSMOS and Munro dataset and the Toxicity Reference Database (ToxRefDB). The combined cOSMOS and Munro dataset was exported from the cosmOS Database [118, https://cosmosdb.eu/cosmosdb.v2/accounts/login/?next=/cosmosdb.v2/ > Computational Methods $>$ TTC Export], and only molecules for which "kidney" or "urinalysis parameters" are recorded first as critical effects were added to the list of nephrotoxicants. Besides information on critical effects stated in the combined COSMOS and Munro dataset, the species and, if available, kidney-related critical effect details were added. The ToxRefDB, which contains lowest effect levels (LELs) of over 
SUB_rat_SystemicCarcinogenic_adult_Urinary_UrinaryBladder, where SUB stands for subchronic), was downloaded from the U.S. EPA Toxicity ForeCaster (ToxCast ${ }^{\mathrm{TM}}$ ) Data website [126, https://www.epa.gov/chemical-research/toxicity-forecaster-toxcasttm-data]. A compound was added to the nephrotoxicants' list if its lowest LEL was only associated with kidney or urinary bladder related endpoints. SMILES codes of identified nephrotoxicants were sourced from Drugbank $[195,196$, https://www.drugbank.ca/],

PubChem

$[199,200$,

https://pubchem.ncbi.nlm.nih.gov/search/],

and

ChemIDplus

$[189$, https://chem.nlm.nih.gov/chemidplus/]. In silico models were queried by using the terms "structural alerts" OR "structural fragments" OR "in silico" OR "QSAR" OR "mechanistic model" OR "mathematical model" AND "nephrotoxicity" OR "kidney toxicity" OR "kidney injury" OR "kidney damage" OR "urinary tract toxicity". 
Appendix A: Kidney assay data available in the ToxCast ${ }^{\mathrm{TM}}$ Dashboard

\begin{tabular}{|c|c|c|c|c|c|}
\hline AssayComponentEndpointName & BiologicalProcessTarget & AssayFunctionType & GeneName & IntendedTargetFamily & Organism \\
\hline NVS_ENZ_pMTHFR & $\begin{array}{l}\text { regulation of catalytic } \\
\text { activity }\end{array}$ & enzymatic activity & $\begin{array}{l}\text { methylenetetrahydrofolate } \\
\text { reductase }(\mathrm{NAD}(\mathrm{P}) \mathrm{H})\end{array}$ & oxidoreductase & pig \\
\hline NVS_ENZ_pMTHFR_Activator & $\begin{array}{l}\text { regulation of catalytic } \\
\text { activity }\end{array}$ & enzymatic activity & $\begin{array}{l}\text { methylenetetrahydrofolate } \\
\text { reductase }(N A D(P) H)\end{array}$ & oxidoreductase & pig \\
\hline NVS_MP_rPBR & receptor binding & binding & translocator protein & transporter & rat \\
\hline OT_AR_ARSRC1_0480 & protein stabilization & binding & androgen receptor & nuclear receptor & human \\
\hline OT_AR_ARSRC1_0960 & protein stabilization & binding & androgen receptor & nuclear receptor & human \\
\hline OT_ER_ERaERa_0480 & protein stabilization & binding & estrogen receptor 1 & nuclear receptor & human \\
\hline OT_ER_ERaERa_1440 & protein stabilization & binding & estrogen receptor 1 & nuclear receptor & human \\
\hline OT_ER_ERaERb_0480 & protein stabilization & binding & estrogen receptor 1 & nuclear receptor & human \\
\hline OT_ER_ERaERb_1440 & protein stabilization & binding & estrogen receptor 1 & nuclear receptor & human \\
\hline OT_ER_ERbERb_0480 & protein stabilization & binding & $\begin{array}{l}\text { estrogen receptor } 2 \text { (ER } \\
\text { beta) }\end{array}$ & nuclear receptor & human \\
\hline
\end{tabular}




\begin{tabular}{|c|c|c|c|c|c|}
\hline OT_ER_ERbERb_1440 & protein stabilization & binding & $\begin{array}{l}\text { estrogen receptor } 2 \text { (ER } \\
\text { beta) }\end{array}$ & nuclear receptor & human \\
\hline OT_FXR_FXRSRC1_0480 & protein stabilization & binding & $\begin{array}{l}\text { nuclear receptor subfamily } \\
1 \text {, group } H \text {, member } 4\end{array}$ & nuclear receptor & human \\
\hline OT_FXR_FXRSRC1_1440 & protein stabilization & binding & $\begin{array}{l}\text { nuclear receptor subfamily } \\
1 \text {, group } H \text {, member } 4\end{array}$ & nuclear receptor & human \\
\hline OT_NURR1_NURR1RXRa_0480 & protein stabilization & binding & retinoid $X$ receptor, alpha & nuclear receptor & human \\
\hline OT_NURR1_NURR1RXRa_1440 & protein stabilization & binding & retinoid $X$ receptor, alpha & nuclear receptor & human \\
\hline OT_PPARg_PPARgSRC1_0480 & protein stabilization & binding & $\begin{array}{l}\text { peroxisome proliferator- } \\
\text { activated receptor gamma }\end{array}$ & nuclear receptor & human \\
\hline OT_PPARg_PPARgSRC1_1440 & protein stabilization & binding & $\begin{array}{l}\text { peroxisome proliferator- } \\
\text { activated receptor gamma }\end{array}$ & nuclear receptor & human \\
\hline TOX21_AR_BLA_Agonist_ch1 & $\begin{array}{l}\text { regulation of transcription } \\
\text { factor activity }\end{array}$ & background control & null & background measurement & human \\
\hline TOX21_AR_BLA_Agonist_ch2 & $\begin{array}{l}\text { regulation of transcription } \\
\text { factor activity }\end{array}$ & reporter gene & null & background measurement & human \\
\hline TOX21_AR_BLA_Agonist_ratio & $\begin{array}{l}\text { regulation of transcription } \\
\text { factor activity }\end{array}$ & reporter gene & androgen receptor & nuclear receptor & human \\
\hline TOX21_AR_BLA_Antagonist_ratio & $\begin{array}{l}\text { regulation of transcription } \\
\text { factor activity }\end{array}$ & reporter gene & androgen receptor & nuclear receptor & human \\
\hline
\end{tabular}




\begin{tabular}{|c|c|c|c|c|c|}
\hline TOX21_AR_BLA_Antagonist_viability & cell proliferation & viability & null & cell cycle & human \\
\hline TOX21_AutoFluor_HEK293_Cell_blue & NA & background control & null & background measurement & human \\
\hline TOX21_AutoFluor_HEK293_Cell_green & NA & background control & null & background measurement & human \\
\hline TOX21_AutoFluor_HEK293_Cell_red & NA & background control & null & background measurement & human \\
\hline TOX21_AutoFluor_HEK293_Media_blue & NA & background control & null & background measurement & human \\
\hline TOX21_AutoFluor_HEK293_Media_green & NA & background control & null & background measurement & human \\
\hline TOX21_AutoFluor_HEK293_Media_red & NA & background control & null & background measurement & human \\
\hline TOX21_ELG1_LUC_Agonist & $\begin{array}{l}\text { regulation of transcription } \\
\text { factor activity }\end{array}$ & reporter gene & $\begin{array}{l}\text { ATPase family, AAA } \\
\text { domain containing } 5\end{array}$ & hydrolase & human \\
\hline TOX21_ERa_BLA_Agonist_ch1 & $\begin{array}{l}\text { regulation of transcription } \\
\text { factor activity }\end{array}$ & background control & null & background measurement & human \\
\hline TOX21_ERa_BLA_Agonist_ch2 & $\begin{array}{l}\text { regulation of transcription } \\
\text { factor activity }\end{array}$ & reporter gene & null & background measurement & human \\
\hline TOX21_ERa_BLA_Agonist_ratio & $\begin{array}{l}\text { regulation of transcription } \\
\text { factor activity }\end{array}$ & reporter gene & estrogen receptor 1 & nuclear receptor & human \\
\hline TOX21_ERa_BLA_Antagonist_ratio & $\begin{array}{l}\text { regulation of transcription } \\
\text { factor activity }\end{array}$ & reporter gene & estrogen receptor 1 & nuclear receptor & human \\
\hline
\end{tabular}




\begin{tabular}{|c|c|c|c|c|c|}
\hline TOX21_ERa_BLA_Antagonist_viability & cell proliferation & viability & null & cell cycle & human \\
\hline TOX21_PPARg_BLA_Agonist_ch1 & $\begin{array}{l}\text { regulation of transcription } \\
\text { factor activity }\end{array}$ & background control & null & background measurement & human \\
\hline TOX21_PPARg_BLA_Agonist_ch2 & $\begin{array}{l}\text { regulation of transcription } \\
\text { factor activity }\end{array}$ & reporter gene & null & background measurement & human \\
\hline TOX21_PPARg_BLA_Agonist_ratio & $\begin{array}{l}\text { regulation of transcription } \\
\text { factor activity }\end{array}$ & reporter gene & $\begin{array}{l}\text { peroxisome proliferator- } \\
\text { activated receptor gamma }\end{array}$ & nuclear receptor & human \\
\hline TOX21_FXR_BLA_agonist_ch1 & $\begin{array}{l}\text { regulation of transcription } \\
\text { factor activity }\end{array}$ & background control & null & background measurement & human \\
\hline TOX21_FXR_BLA_agonist_ch2 & $\begin{array}{l}\text { regulation of transcription } \\
\text { factor activity }\end{array}$ & background control & null & background measurement & human \\
\hline TOX21_FXR_BLA_agonist_ratio & $\begin{array}{l}\text { regulation of transcription } \\
\text { factor activity }\end{array}$ & reporter gene & $\begin{array}{l}\text { nuclear receptor subfamily } \\
1 \text {, group } \mathrm{H} \text {, member } 4\end{array}$ & nuclear receptor & human \\
\hline TOX21_FXR_BLA_antagonist_ratio & $\begin{array}{l}\text { regulation of transcription } \\
\text { factor activity }\end{array}$ & reporter gene & $\begin{array}{l}\text { nuclear receptor subfamily } \\
1 \text {, group } \mathrm{H} \text {, member } 4\end{array}$ & nuclear receptor & human \\
\hline TOX21_FXR_BLA_antagonist_viability & cell proliferation & viability & null & cell cycle & human \\
\hline TOX21_PPARd_BLA_agonist_ch1 & $\begin{array}{l}\text { regulation of transcription } \\
\text { factor activity }\end{array}$ & background control & null & background measurement & human \\
\hline
\end{tabular}




\begin{tabular}{|c|c|c|c|c|c|}
\hline TOX21_PPARd_BLA_agonist_ch2 & $\begin{array}{l}\text { regulation of transcription } \\
\text { factor activity }\end{array}$ & background control & null & background measurement & human \\
\hline TOX21_PPARd_BLA_agonist_ratio & $\begin{array}{l}\text { regulation of transcription } \\
\text { factor activity }\end{array}$ & reporter gene & $\begin{array}{l}\text { peroxisome proliferator- } \\
\text { activated receptor delta }\end{array}$ & nuclear receptor & human \\
\hline TOX21_PPARd_BLA_antagonist_ratio & $\begin{array}{l}\text { regulation of transcription } \\
\text { factor activity }\end{array}$ & reporter gene & $\begin{array}{l}\text { peroxisome proliferator- } \\
\text { activated receptor delta }\end{array}$ & nuclear receptor & human \\
\hline TOX21_PPARd_BLA_antagonist_viability & cell proliferation & viability & null & cell cycle & human \\
\hline TOX21_PPARg_BLA_antagonist_ratio & $\begin{array}{l}\text { regulation of transcription } \\
\text { factor activity }\end{array}$ & reporter gene & $\begin{array}{l}\text { peroxisome proliferator- } \\
\text { activated receptor gamma }\end{array}$ & nuclear receptor & human \\
\hline TOX21_PPARg_BLA_antagonist_viability & cell proliferation & viability & null & cell cycle & human \\
\hline TOX21_VDR_BLA_agonist_ch1 & $\begin{array}{l}\text { regulation of transcription } \\
\text { factor activity }\end{array}$ & background control & null & background measurement & human \\
\hline TOX21_VDR_BLA_agonist_ch2 & $\begin{array}{l}\text { regulation of transcription } \\
\text { factor activity }\end{array}$ & background control & null & background measurement & human \\
\hline TOX21_VDR_BLA_agonist_ratio & $\begin{array}{l}\text { regulation of transcription } \\
\text { factor activity }\end{array}$ & reporter gene & $\begin{array}{l}\text { cytochrome P450, family } \\
24 \text {, subfamily A, } \\
\text { polypeptide } 1\end{array}$ & сур & human \\
\hline TOX21_VDR_BLA_antagonist_ratio & $\begin{array}{l}\text { regulation of transcription } \\
\text { factor activity }\end{array}$ & reporter gene & $\begin{array}{l}\text { cytochrome P450, family } \\
24 \text {, subfamily A, } \\
\text { polypeptide } 1\end{array}$ & cyp & human \\
\hline
\end{tabular}




\begin{tabular}{|c|c|c|c|c|c|}
\hline TOX21_VDR_BLA_antagonist_viability & cell proliferation & viability & null & cell cycle & human \\
\hline TOX21_FXR_BLA_agonist_viability & cell proliferation & viability & null & cell cycle & human \\
\hline TOX21_ERa_BLA_Antagonist_ch1 & $\begin{array}{l}\text { regulation of transcription } \\
\text { factor activity }\end{array}$ & background control & null & background measurement & human \\
\hline TOX21_ERa_BLA_Antagonist_ch2 & $\begin{array}{l}\text { regulation of transcription } \\
\text { factor activity }\end{array}$ & background control & null & background measurement & human \\
\hline TOX21_FXR_BLA_Antagonist_ch1 & $\begin{array}{l}\text { regulation of transcription } \\
\text { factor activity }\end{array}$ & background control & null & background measurement & human \\
\hline TOX21_FXR_BLA_Antagonist_ch2 & $\begin{array}{l}\text { regulation of transcription } \\
\text { factor activity }\end{array}$ & background control & null & background measurement & human \\
\hline TOX21_PPARd_BLA_Agonist_viability & cell proliferation & viability & null & cell cycle & human \\
\hline TOX21_PPARd_BLA_Antagonist_ch1 & $\begin{array}{l}\text { regulation of transcription } \\
\text { factor activity }\end{array}$ & background control & null & background measurement & human \\
\hline TOX21_PPARd_BLA_Antagonist_ch2 & $\begin{array}{l}\text { regulation of transcription } \\
\text { factor activity }\end{array}$ & background control & null & background measurement & human \\
\hline TOX21_PPARg_BLA_Antagonist_ch1 & $\begin{array}{l}\text { regulation of transcription } \\
\text { factor activity }\end{array}$ & background control & null & background measurement & human \\
\hline TOX21_PPARg_BLA_Antagonist_ch2 & regulation of transcription & background control & null & background measurement & human \\
\hline
\end{tabular}




\begin{tabular}{|c|c|c|c|c|c|}
\hline & factor activity & & & & \\
\hline TOX21_VDR_BLA_Antagonist_ch1 & $\begin{array}{l}\text { regulation of transcription } \\
\text { factor activity }\end{array}$ & background control & null & background measurement & human \\
\hline TOX21_VDR_BLA_Antagonist_ch2 & $\begin{array}{l}\text { regulation of transcription } \\
\text { factor activity }\end{array}$ & background control & null & background measurement & human \\
\hline TOX21_AR_BLA_Antagonist_ch1 & $\begin{array}{l}\text { regulation of transcription } \\
\text { factor activity }\end{array}$ & background control & null & background measurement & human \\
\hline TOX21_AR_BLA_Antagonist_ch2 & $\begin{array}{l}\text { regulation of transcription } \\
\text { factor activity }\end{array}$ & background control & null & background measurement & human \\
\hline TOX21_VDR_BLA_Agonist_viability & cell proliferation & viability & null & cell cycle & human \\
\hline NCCT_HEK293T_CellTiterGLO & cytotoxicity & viability & null & cell cycle & human \\
\hline
\end{tabular}

For additional information on assays, please reference the ToxCast ${ }^{\mathrm{TM}}$ dashboard. 


\section{Appendix B: Kidney and urinary bladder related toxicity endpoints available in ToxRefDB}

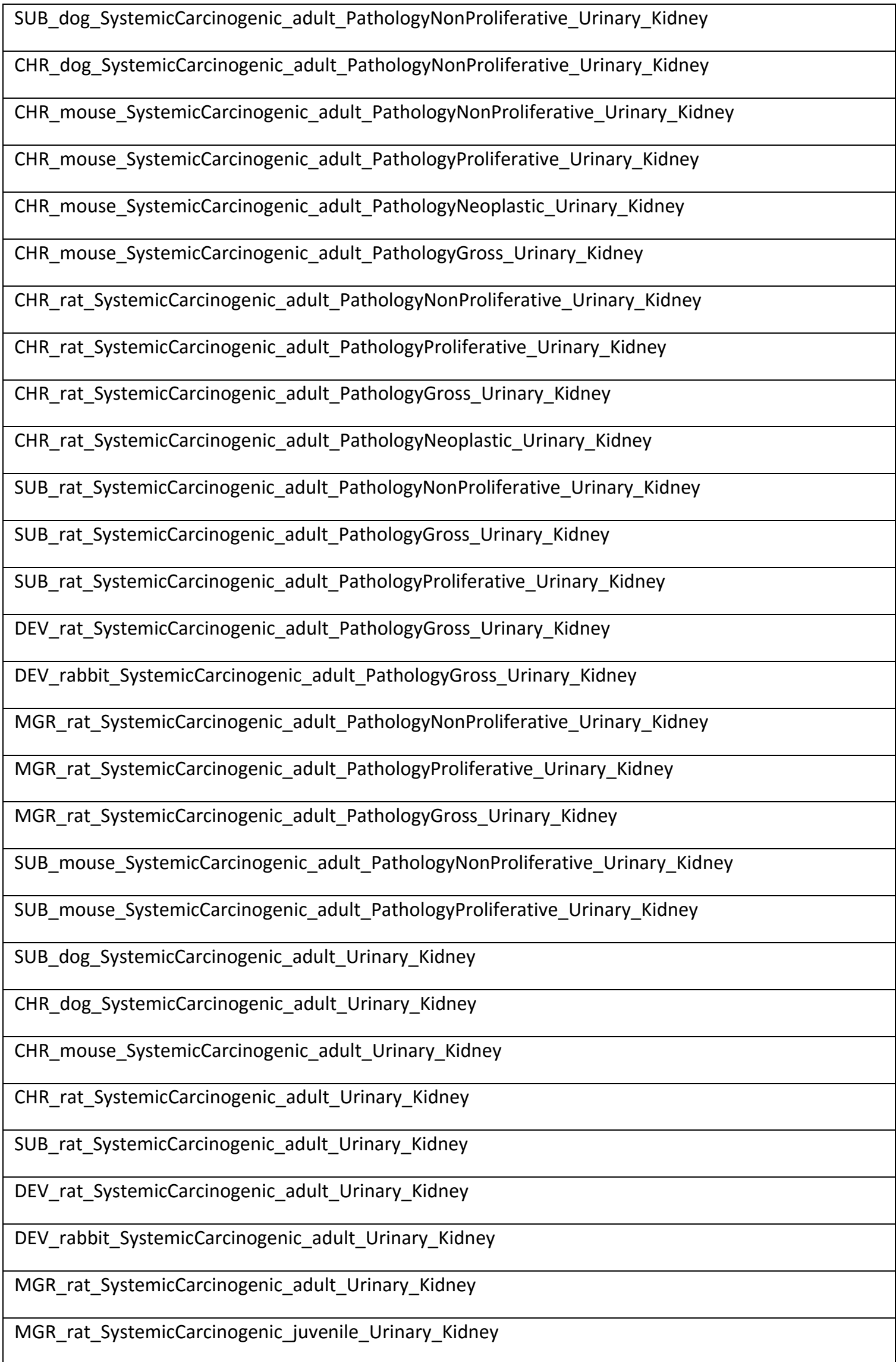




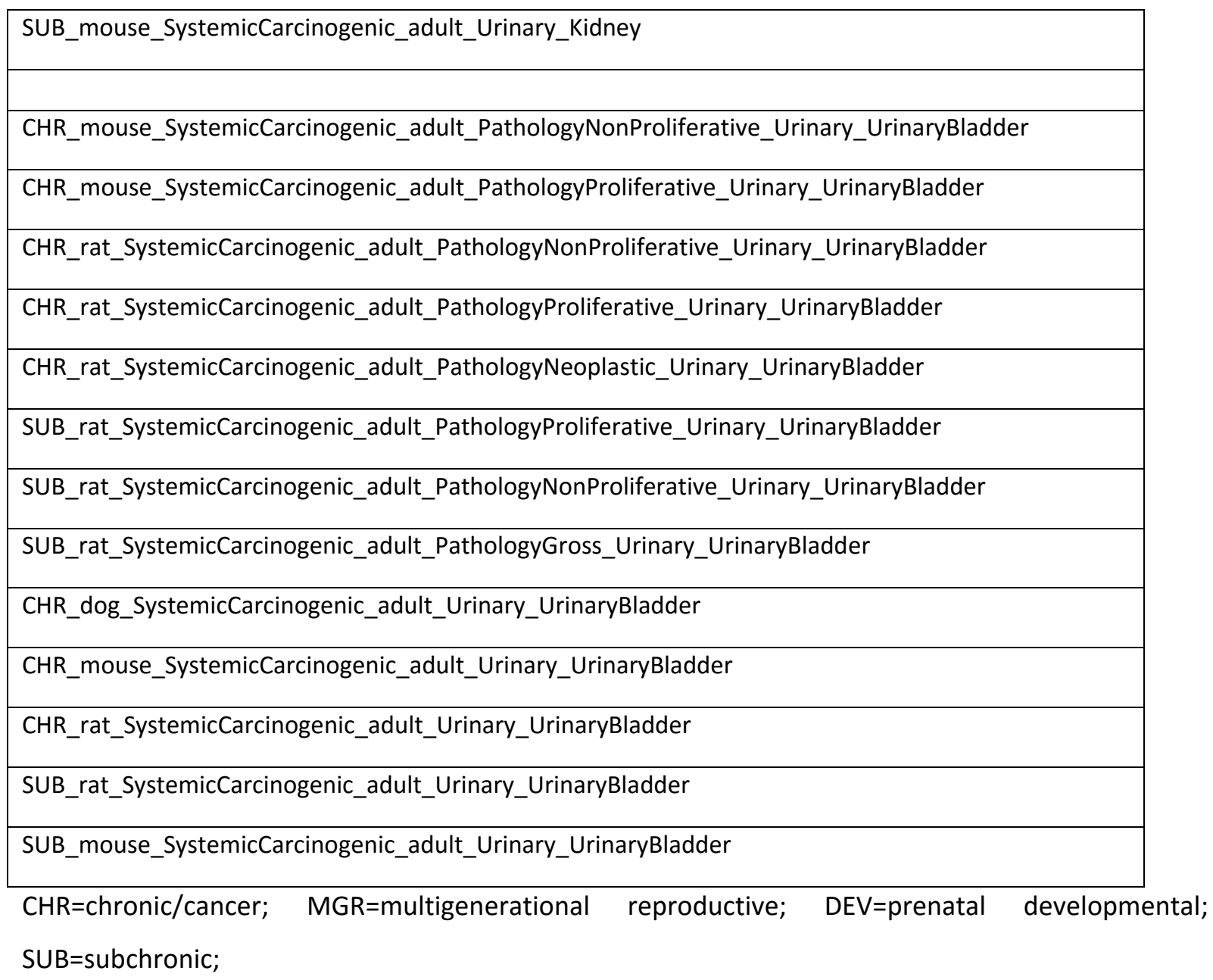

\section{Appendix C: Description of (Q)SAR models associated with kidney and bladder toxicity}

C.1 Munday et al. [262]

Munday et al. [262] aimed to derive structural alerts for rat nephrotoxicity from 16 1,2- and 1,4naphthoquinones. Some naphthoquinones, e.g. 2-hydroxy-1,4-naphthoquinone and 2-amino-1,4naphthoquinone, had been found to be nephrotoxic, mainly causing renal tubular necrosis in rats associated with presence of casts in the tubules [262,271,272]. 2-hydroxy-1,4-naphthoquinone, the active component in henna, produced fatal renal tubular necrosis in a child who was cutaneously treated with henna [273]. The mechanism of renal tubular necrosis induced by the 1,4naphthoquinones was, and still appears to be, unknown. Munday et al. [262,272] hypothesised that nephrotoxicity was a result of tautomerism of hydroxyl or amino 1,4-quinolones to strongly reactive 1,2-naphthoquinones or 1,2-naphthoquinoneimines. However, the results of the study suggest that this hypothesis is wrong. The results did not allow for the definitive identification of structural features associated with naphthoquinone-induced nephrotoxicity or the conclusive determination of 
the mechanism. However, this study confirmed that 2-hydroxy-1,4-naphthoquinone and 4-amino1,2,-naphthoquinone were extremely toxic to the kidney. Several alterations in structure of the above compounds caused the following changes in their toxic effect to the kidney: methylation of the amino group substantially increased nephrotoxicity, whilst methylation of the hydroxyl group, arylation of the amino-group and substitution with a chloro or amino group in the 3-position of the quinone ring eliminated nephrotoxicity. It was also found that substitution with small substituents i.e. methyl or ethyl decreases the extent of renal tubular damage - the larger the size of alkyl group, the greater the reduction of renal damage.

\section{C.2 Pizzo et al. [263]}

Pizzo et al. [263] conducted a study to evaluate, identify and group substructures into six structural alerts recognised as being toxic to the kidney and / or urinary tract using repeated-dose toxicity studies on rats taken from the Hazard Evaluation Support System (HESS) database. SAs were selected based on their likelihood ratio (LR) and percentage of true positives. These alerts were encoded as SMARTS (SMiles ARbitrary Target Specification). A plausible mechanistic explanation for these substructures to cause nephrotoxicity was only provided for the $2^{\text {nd }}, 3^{\text {rd }}, 5^{\text {th }}$ and $6^{\text {th }}$ SAs.

The $2^{\text {nd }}$ SA identified is sulphanilamide, which belongs to the class of sulphonamides. According to the literature, sulphonamides can cause obstructive nephropathy as they are insoluble in acidic urine, which causes them to precipitate as crystals in the tubules [87]. SA 3 is found in benzonitriles which have been reported to be harmful to the kidney due to adverse effects leading to cytotoxicity in the human embryonic renal cell line HEK293T [274]. SA 5 is chloroform, which is also reported as a structural alert in other studies, including Myshkin et al. [265]. Chloroform is believed to cause nephrotoxicity via metabolism by P450 enzymes into toxic metabolites which may induce renal cancer through cytotoxicity eliciting regenerative cell proliferation [274]. SA 6 is biphenyl; according to Pizzo et al. [263], biphenyl was identified seven times in the dataset of 89 active kidney toxicants, out of which five cases were found in nephrotoxic molecules. Biphenyls cause haematuria, increased urinary $\mathrm{pH}$, formation of calculi inducing urinary tract tumours $[263,275]$. According to ChemDraw Professional (version:16.0.1.4 (77)), SA 1 and 4 are benzenesulfonic acid and hepta-1,5-diene, respectively. Most of the above alerts were reproduced in the study by Myshkin et al. [265].

\section{C.3 Derek Nexus}

Derek Nexus is a knowledge-based expert system that uses SAs to provide in silico prediction of toxicity [264]. As well as the key mechanisms mentioned earlier, Derek Nexus may identify 
compounds elicting nephrotoxicity via additional mechanisms. Examples of these mechanisms include: necrosis and fibrosis of the renal medullary interstitium; drug-induced ureteral obstruction (when drug causes blockage in one or both of the ureters leading from kidneys to the bladder) and drug-induced formation of cholesterol emboli. Also, Derek Nexus EREK may trigger a warning for $\alpha 2 \mu$-globulin nephropathy. Any structural alerts are identified in the original structure as highlighted toxicophores. A list of key literature references is provided, along with, in some cases, a proposed mechanism.

\section{C.4 Myshkin et al. [265]}

Myshkin et al. [265] described the construction and validation of QSAR models based on a database of organ-level toxicity and the identification of toxicophores. QSAR models were generated to predict organ toxicity endpoints, including "nephrotoxicity" with subcategories for "kidney necrosis", "kidney relative weight gain" and "nephron injury", using a recursive partitioning algorithm. According to the authors, the models demonstrated good predictive performance overall. When developing the compound sets, chemicals that were known to cause the toxicity (positives) and chemicals known not to cause toxicity (negatives) were included. The positives that were correctly predicted by the models were then clustered based on common toxicophore substructures by the JKlustor 5.9.0 utility from ChemAxon.

A total of 192 toxicophores were identified for all nephrotoxicity endpoints. However, the endpoints "kidney weight gain", "nephron injury" and "nephrotoxicity" are unspecific toxicity endpoints with regard to attempting to identify a mechanistic explanation for the nephrotoxic effect. These three endpoints could be associated with all of the nephrotoxicity pathways discussed in more detail below. Some of the substructures identified by Myskin et al. [265] were also identified in the other studies mentioned above; for example, chloroform, providing further justification and confirmation. In addition, some of the substructures identified are also relatively unspecific, e.g. cyclohexane or chlorobenzene. In the case of chlorobenzene, some more specific related substructures have been proposed, such as 1,2-dichlorobenzene, 1,3-dichlorobenzene or 4chlorophenol. For this reason, it may be useful to study these substructures in more detail and find more defined alerts relating to nephrotoxicity.

\section{C.5 Jolivette and Anders [266]}

Jolivette and Anders [266] developed a linear QSAR model to predict the nephrotoxicity of 9 haloalkenes. Haloalkenes are high-volume chemicals and common environmental pollutants. 
Bioactivation of haloalkanes occurs to form reactive intermediates. This process involves the formation of hepatic glutathione S-conjugates, which are then hydrolysed by peptidases into cysteine S-conjugates. Cysteine S-conjugates subsequently undergo bioactivation, by renal cysteine conjugate lyases, to form the nephrotoxic intermediates. The reaction of glutathione with haloalkenes is catalysed by microsomal (MGST1) and cytosolic glutathione transferases (cGST) [266]. In this study, a computational chemistry approach was used to test the hypothesis that an SAR exists and that $E_{\text {LUMo }}$ (energies of the lowest unoccupied molecular orbitals) values can be used to predict the ability of rat liver MGST1 to catalyse the reaction of glutathione with haloalkenes. No, or a low level of, conjugate formation was detected for four of the nine molecules investigated. A linear relationship was found between the natural logarithms of the specific activities for the glutathione conjugation reaction catalysed by rat liver MGST1 and $E_{L U M O}$ values for hexafluoropropene, 2(fluoromethoxy)-1,1,3,3,3-pentafluoro-1-propene, 1,1,2-trichloro-3,3,3-trifluoro-1-propene and 1,1dibromo-2,2-difluoroethene. This linear relationship corresponds only to four data points and cannot be extrapolated to $E_{\text {LUmo }}$ values outside of the range -1.14 to $-0.73 \mathrm{eV}$. When the $E_{\text {LUmo }}$ value for tetrachloroethene was added to those of the previously mentioned four compounds and compared with the natural logarithms, a linear relationship was not seen. It was found that haloalkenes with more negative $E_{\text {LUMO }}$ values demonstrate a greater specific activity for the enzyme-catalysed reaction of glutathione conjugation than haloalkenes with less negative $\mathrm{E}_{\mathrm{LUmo}}$ values. This indicates that the chemical reactivity of the substrate plays a crucial role in the rate at which the glutathionedependent biotransformation of the haloalkenes takes place.

\section{C.6 Barratt [99]}

$\alpha 2 \mu$-globulin nephropathy occurs in male rats as a result of a compound's binding affinity to $\alpha_{2 \mu^{-}}$ globulin, which causes the chemical-protein complex to accumulate in renal lysosomes [99]. This leads to tubular necrosis and eventually cell death. Barratt [99] derived two QSAR models to screen for the potential of a compound to induce $\alpha 2 \mu$-globulin nephropathy by multiple regression analysis and principal components analysis using the following properties: negative charge density of the binding molecule, molecular volume, and inertial axis lengths. The QSAR model based on multiple regression analysis alone did not accommodate all of the molecular features that allowed accurate predictions of chemicals that may cause $\alpha 2 \mu$-globulin nephropathy. Therefore, a previous dataset by Bomhard et al. [276] consisting of 43 aliphatic and alicyclic hydrocarbon structures was added and subjected to a principal components analysis. The toxicological endpoint assessed in Bomhard et al. [276] was $\alpha 2 \mu$-accumulation in renal lysosomes in male rats. It was found that for a molecule to cause $\alpha 2 \mu$-globulin nephropathy, its size and shape should be so that it fits with the binding site on 
$\alpha 2 \mu$-globulin. It should also have a hydrogen bond acceptor. Lastly, hydrophobic interactions were found to be a contributing factor but not to a significant extent when included in either QSAR. The shape, size and electronegativity elements related to active compounds were incorporated in both QSARs.

Barratt [99] concluded that the combination of the two QSARs is useful in identifying molecular structures with a potential to cause $\alpha 2 \mu$-globulin nephropathy. The applicability domain of both QSARs was not discussed. Furthermore, $\alpha 2 \mu$-globulin nephropathy has been acknowledged as an adverse effect specific to male rats and little relevant to human health as $\alpha 2 \mu$-globulin is not synthesised in the human liver [99]. Hence, these models may only be applied to assess whether compounds which have been linked to nephrotoxicity in male rats induce these effects via the $\alpha 2 \mu$ globulin pathway.

\section{C.7 Lee et al. [252]}

Lee et al. [252] developed binary classification QSAR prediction models for three nephrotoxicity mechanisms: tubular necrosis, interstitial nephritis, and tubulo-interstitial nephritis. These models were built using two data sets, i.e. parent compounds (251 nephrotoxicants and 387 nonnephrotoxicants) and their urinary metabolites (307 nephrotoxicants and 233 non-nephrotoxicants) based on clinical trials and post-marketing surveillance reports. A list of the parent and metabolite compounds was not published. Models were computed using a support vector machine and 20 descriptors with highest information gains in the form of eight different fingerprints for parent and metabolite sets and each of the three mechanisms. According to the authors, the predicted accuracies of the models for each type of kidney injury were better than $83 \%$ for external validation sets. This indicates that the models used could prove to be useful in identifying potentially nephrotoxic compounds.

Substructural fragments were analysed and were documented alongside the frequency of fragment enrichment factors. The selected eight substructures were common to both datasets for all of the above three nephrotoxicity mechanisms. Lee et al. [252] concluded that consideration of the metabolism of a chemical is important to predict its nephrotoxicity potential. When comparing the number of nephrotoxicants and non-nephrotoxicants with a specified fragment of the metabolite set to respective numbers of the parent compound set, the number of nephrotoxicant metabolites increased dramatically. This is due to the bioactivation of a potentially non-nephrotoxic compound into a toxic metabolite. Also, when these alerts were compared approximately to those found by 
Pizzo et al. [263], similarities were not observed at first sight. Lee et al. [252] have provided a link that offers free access to the software on their website. However, this link does not appear to be working at this time: http://bmdrc.org/DemoDownload.

\section{C.8 Matthews et al. [267]}

Matthews et al. [267] created QSAR models to predict drug-induced urinary tract toxicity in humans on the basis of adverse events reported post marketing approval. Six endpoints of urinary tract injury were considered, namely nephropathies, acute renal disorders, bladder disorders, blood in urine, urolithiases and kidney function tests. Four QSAR approaches were applied using the following software: MC4PC, BioEpisteme, MDL QSAR and Leadscope Predictive Data Miner. The best predictive performance was achieved for the endpoints kidney function test with $87.7 \%$ specificity, $43.3 \%$ sensitivity and $91.6 \%$ coverage, and nephropathies with of $81.5 \%$ specificity, $49.5 \%$ sensitivity and $91.4 \%$ coverage. One of the limitations of these models is the variable quality of the postmarketing reported adverse event data used which may be compromised through non-uniform reporting of an adverse effect and its occurrence in patients who are often subject to multi-drug therapy.

\section{C.9 Antczak et al. [268]}

This study aimed to link physico-chemical features to drug-induced transcriptional responses and phenotypic outcome using a multivariate statistical approach. A number of KEGG pathways, which were reported to be significantly perturbed by nephrotoxic compounds under consideration in this study, may be specifically associated with nephrotoxicity [268]. The model showed that nephrotoxic substances are characterised by high polarisability, low electronegativity and low molecular symmetry.

\section{C.10 Hammann et al. [269]}

For this study, Hammann et al. [269] use decision tree inference analysis, a machine learning method, based on the chemical, physical, and structural properties and adverse drug reactions of 507 drugs. As decision tree inference algorithms, classification and regression tree (CART) and chisquared automatic interaction detector (CHAID) were selected. Both models performed well, with CART and CHAID model corrected classification rates (CCRs) of 88.6 and $84.7 \%$, respectively. The CART model highlights that amine functions, sulphur, and carboaromatic ring structures have an influence on a drug's potential to cause nephrotoxicity. For substances safer to the kidney, CHAID 
model found few aromatic atoms $(<19)$, a basic $\mathrm{pK}_{\mathrm{a}}<10.71$, van der Waals surface area $<1,014.5 \AA^{2}$, and $\log P$ values $>2.43$.

\section{C.11 Lei et al. [270]}

Lei et al. [270] used a mouse intraperitoneal urinary tract toxicity data set of 258 chemicals from the ChemIDplus public database to develop eight qualitative and quantitative structure-activity relationship (QSAR), i.e. classification and regression, models to predict urinary tract toxicity. The recursive feature elimination method incorporated with random forests (RFE-RF) was applied for dimension reduction, followed by the utilisation of eight machine learning approaches for QSAR modelling, i.e., relevance vector machine (RVM), support vector machine (SVM), regularized random forest (RRF), C5.0 trees, eXtreme gradient boosting (XGBoost), AdaBoost.M1, SVM boosting (SVMBoost), and RVM boosting (RVMBoost). Among these, RVMBoost based on the RBF kernel accomplishes the best quantitative and qualitative predictions for the test set (MCC of 0.787, AUC of 0.893 , sensitivity of $89.6 \%$, specificity of $94.1 \%$, and global accuracy of $90.8 \%)$. All chemicals included in this study are within the application domain coverage. Overall, a reliable prediction is achieved by both regression and classification models developed by the SVMBoost approach.

Bibliography:

[1] Mehta RL, Pascual MT, Soroko S, et al. Spectrum of acute renal failure in the intensive care unit: the PICARD experience. Kidney Int. 2004;66:1613-1621.

[2] Uchino S, Kellum JA, Bellomo R, et al. Acute renal failure in critically ill patients: a multinational, multicenter study. JAMA [Internet]. 2005;294:813-818. Available from: http://www.ncbi.nlm.nih.gov/pubmed/21787472.

[3] Zhang L, Wang $\mathrm{M}$, Wang $\mathrm{H}$. Acute renal failure in chronic kidney disease - clinical and pathological analysis of 104 cases. Clin. Nephrol. [Internet]. 2005;63:346-350. Available from: https://www.ncbi.nlm.nih.gov/pubmed/15909593.

[4] Fung M, Thornton A, Mybeck K, et al. Evaluation of the characteristics of safety withdrawal of prescription drugs from worldwide pharmaceutical markets - 1960 to 1999. Drug Inf. J. [Internet]. 2001;35:293-317. Available from: http://journals.sagepub.com/doi/10.1177/009286150103500134.

[5] Zaza G, Granata S, Tomei P, et al. Personalization of the immunosuppressive treatment in renal transplant recipients: the great challenge in "omics" medicine. Int. J. Mol. Sci. [Internet]. 
2015;16:4281-4305. Available from: http://www.ncbi.nlm.nih.gov/pubmed/25690039.

[6] Folli F, Guzzi V, Perego L, et al. Proteomics reveals novel oxidative and glycolytic mechanisms in type 1 diabetic patients' skin which are normalized by kidney-pancreas transplantation. PLoS One [Internet]. 2010;5:e9923. Available from: http://www.ncbi.nlm.nih.gov/pubmed/20360867.

[7] NASEM (The National Academies of Sciences, Engineering and Medicine). Using 21st century science to improve risk-related evaluations [Internet]. Washington, D.C.: National Academies Press; 2017. Available from: https://www.nap.edu/catalog/24635.

[8] Przybylak KR, Cronin MTD. In silico models for drug-induced liver injury - current status. Expert Opin. Drug Metab. Toxicol. 2012;8:201-217.

[9] Hewitt M, Przybylak KR. In silico models for hepatotoxicity. In: Benfenati E, editor.In silico methods for predicting drug toxicity. Methods in molecular biology [Internet]. Volume 142. New York, USA: Humana Press; 2016. p. 201-236. Available from: http://link.springer.com/10.1007/978-1-4939-3609-0_11.

[10] Cronin MTD, Richarz A-N. Relationship between adverse outcome pathways and chemistrybased in silico models to predict toxicity. Appl. Vitr. Toxicol. [Internet]. 2017;3:286-297. Available from: http://online.liebertpub.com/doi/10.1089/aivt.2017.0021. * Valuable insight into AOP-based modelling

[11] Sturla SJ, Boobis AR, FitzGerald RE, et al. Systems toxicology: from basic research to risk assessment. Chem. Res. Toxicol. 2014;27:314-329.

[12] Naughton CA. Drug-induced nephrotoxicity. Am. Fam. Physician. 2008;78:743-750. Comprehensive review of nephrotoxicants and mechanisms

[13] Farooqi S, Dickhout JG. Major comorbid disease processes associated with increased incidence of acute kidney injury. World J. Nephrol. [Internet]. 2016;5:139-146. Available from: http://www.wjgnet.com/2220-6124/full/v5/i2/139.htm.

[14] Van Vleet TR, Schnellmann RG. Toxic nephropathy: environmental chemicals. Semin. Nephrol. 2003;23:500-508.

[15] Cronin MTD, Enoch SJ, Mellor CL, et al. In silico prediction of organ level toxicity: linking chemistry to adverse effects. Toxicol. Res. 2017;33:173-182. ** In-depth review of in silico models for hepatotoxicants

[16] Bhattacharya S, Shoda LKM, Zhang Q, et al. Modeling drug- and chemical-induced hepatotoxicity with systems biology approaches. Front. Physiol. 2012;3:1-18, article 462.

[17] Diaz Ochoa JG, Bucher J, Péry ARR, et al. A multi-scale modeling framework for individualized, spatiotemporal prediction of drug effects and toxicological risk. Front. Pharmacol. 


\section{3;3:article 204, 1-11. ** Sophisticated modelling approach}

[18] Sluka JP, Fu X, Swat M, et al. A liver-centric multiscale modeling framework for xenobiotics. PLoS One. 2016;11:1-40, e0162428. ** Sophisticated modelling approach

[19] Sexton J. Chronic kidney disease - a refresher. Pharm. J. 2013;291:85-88.

[20] Perazella MA. Renal vulnerability to drug toxicity. Clin. J. Am. Soc. Nephrol. 2009;4:12751283. * Comprehensive review of nephrotoxicants and mechanisms

[21] Rang HP, Ritter JM, Flower RJ, et al., editors. Rang \& Dale's pharmacology. 8th ed. Edinburgh: Elsevier/Churchill Livingstone; 2016.

[22] John R, Herzenberg AM. Renal toxicity of therapeutic drugs. J. Clin. Pathol. 2009;62:505-515. * Comprehensive review of nephrotoxicants and mechanisms

[23] Boroujerdi M, editor. Pharmacokinetics and toxicokinetics. Boca Raton: CRC Press, Taylor \& Francis Group; 2015.

[24] Blatt AE, Liebman SE. Drug induced acute kidney injury. In: Alper EJ, Lang VJ, editors. Hosp. Med. Clin. [Internet]. Elsevier Inc.; 2013. p. e525-e541. Available from: http://dx.doi.org/10.1016/j.ehmc.2013.04.003. * Comprehensive review of nephrotoxicants and mechanisms

[25] Vaidya VS, Bonventre J V., Ferguson MA. Biomarkers of acute kidney injury. In: McQeen CA, Schnellmann RG, editors. Comprehensive Toxicology. Volume 7. Oxford, UK: Elsevier; 2010. p. 197-211. ** Information on novel biomarkers is valuable to future modelling of nephrotoxicity

[26] OECD. AOP Knowledge Base (AOP-KB) [Internet]. 2017 [cited 2018 Feb 20]. Available from: http://aopkb.org.

[27] Ellison CM, Piechota P, Madden JC, et al. Adverse outcome pathway (AOP) informed modeling of aquatic toxicology: QSARs, read-across, and interspecies verification of modes of action. Environ. Sci. Technol. [Internet]. 2016;50:3995-4007. Available from:

https://pubs.acs.org/doi/pdf/10.1021/acs.est.5b05918.

[28] AOP Wiki [Internet]. [cited 2018 Feb 20]. Available from: https://aopwiki.org/.

[29] Drewe WC, Surfraz MB. Adverse outcome pathways for the nephrotoxicity of non-steroidal anti-inflammatory drugs. SOT. San Diego, USA; 2015. p. 22-26 March.

[30] Naesens M, Kuypers DRJ, Sarwal M. Calcineurin inhibitor nephrotoxicity. Clin. J. Am. Soc. Nephrol. 2009;4:481-508.

[31] Wilmes A, Limonciel A, Leonard MO, et al. Translational biomarkers, in vitro and in vivo. In: Bal-Price A, Jennings $P$, editors. In vitro toxicology systems, methods in pharmacology and toxicology. [Internet]. New York: Springer Science+Business Media; 2014. p. 459-478. 
Available from: http://link.springer.com/10.1007/978-1-4939-0521-8.

[32] Brown NJ, Vaughan DE. Angiotensin-converting enzyme inhibitors. Circulation. 1998;97:14111420.

[33] Palmer BF. Renal dysfunction complicating the treatment of hypertension. N. Engl. J. Med. 2002;347:1256-1261.

[34] Fanos V, Cataldi L. Amphotericin B-induced nephrotoxicity: a review. J. Chemother. 2000;12:463-470.

[35] Evenepoel P. Toxic nephropathy due to drugs and poisons. In: Jörres A, Ronco C, Kellum JA, editors. Management of acute kidney problems. Heidelberg, Germany: Springer; 2010. p. $317-328$.

[36] OECD. Report of the workshop on using mechanistic information in forming chemical categories. Series on Testing and Assessment No.138. ENV/JM/MONO(2011)8. 2011; Available from: http://www.oecd.org/officialdocuments/displaydocumentpdhttp://www.oecd.org/officialdo cuments/publicdisplaydocumentpdf/?cote=env/jm/mono(2011)8\&doclanguage=en .

[37] Drewe WC, Cayley A, Benz RD, et al. Identification of adverse outcome pathways for the nephrotoxicity of nucleoside and nucleotide anti-viral drugs. SOT. Phoenix, USA; 2014. p. 27th March.

[38] Wunnapuk K, Liu X, Peake P, et al. Renal biomarkers predict nephrotoxicity after paraquat. Toxicol. Lett. [Internet]. 2013;222:280-288. Available from: http://dx.doi.org/10.1016/j.toxlet.2013.08.003.

[39] Schena FP, Serino G, Sallustio F. MicroRNAs in kidney diseases: new promising biomarkers for diagnosis and monitoring. Nephrol. Dial. Transplant. 2014;29:755-763.

[40] Bhatt K, Zhou L, Mi Q-S, et al. MicroRNA-34a is induced via p53 during cisplatin nephrotoxicity and contributes to cell survival. Mol. Med. [Internet]. 2010;16:409-416. Available from: http://www.pubmedcentral.nih.gov/articlerender.fcgi?artid=2935954\&tool=pmcentrez\&ren dertype=abstract.

[41] Ferguson MA, Vaidya V, Bonventre J V. Biomarkers of nephrotoxic acute kidney injury. Toxicology [Internet]. 2008;245:182-193. Available from: http://linkinghub.elsevier.com/retrieve/pii/S0300483X07008487.

[42] Bonventre J V, Vaidya VS, Schmouder R, et al. Next-generation biomarkers for detecting kidney toxicity. Nat. Biotechnol. 2010;28:436-440. * Information on novel biomarkers is valuable to future modelling of nephrotoxicity

[43] Zager RA, Johnson ACM, Becker K. Plasma and urinary heme oxygenase-1 in AKI. J. Am. Soc. 
Nephrol. [Internet]. 2012;23:1048-1057. Available from: http://www.jasn.org/cgi/doi/10.1681/ASN.2011121147.

[44] Walker RJ, Endre ZH. Cellular mechanisms of drug nephrotoxicity. In: Alpern RJ, Caplan MJ, Moe OW, editors. Seldin and Giebisch's the kidney: hpysiology and pathophysiology. [Internet]. Fifth. London, UK: Academic Press/Elsevier; 2013. p. 2889-2932. Available from: http://linkinghub.elsevier.com/retrieve/pii/B9780123814623000859. ** Comprehensive review of mechanisms of nephrotoxicity

[45] Mingeot-Leclercq M-P, Tulkens PM. Aminoglycosides: nephrotoxicity. Antimicrob. Agents Chemother. [Internet]. 1999;43:1003-1012. Available from:

http://www.ncbi.nlm.nih.gov/pubmed/10223907.

[46] Dickenmann M, Oettl T, Mihatsch MJ. Osmotic nephrosis: acute kidney injury with accumulation of proximal tubular lysosomes due to administration of exogenous solutes. Am. J. Kidney Dis. 2008;51:491-503.

[47] Krishnan N, Perazella MA. Drug-induced acute interstitial nephritis: pathology, pathogenesis, and treatment. Iran. J. Kidney Dis. 2015;9:3-13.

[48] Kodner CM, Kudrimoti A. Diagnosis and management of acute interstitial nephritis. Am. Fam. Physician. 2003;67:2527-2534.

[49] Ursem CJ, Kruhlak NL, Contrera JF, et al. Identification of structure-activity relationships for adverse effects of pharmaceuticals in humans. Part A: use of FDA post-market reports to create a database of hepatobiliary and urinary tract toxicities. Regul. Toxicol. Pharmacol. [Internet]. 2009;54:1-22. Available from: http://dx.doi.org/10.1016/j.yrtph.2008.12.009.

[50] Vaidya VS, Ferguson MA, Bonventre J V. Biomarkers of acute kidney injury. Annu. Rev. Pharmacol. Toxicol. [Internet]. 2008;48:463-493. Available from: papers://347a0d64-8b484dcf-b0a7-00f094a7599b/Paper/p33.

[51] Hudkins KL, Giachelli CM, Cui Y, et al. Osteopontin expression in fetal and mature human kidney. J. Am. Soc. Nephrol. 1999;10:444-457.

[52] Schmid M, Dalela D, Tahbaz R, et al. Novel biomarkers of acute kidney injury: evaluation and evidence in urologic surgery. World J. Nephrol. [Internet]. 2015;4:160-168. Available from: http://www.wjgnet.com/2220-6124/full/v4/i2/160.htm.

[53] Pabla N, Dong Z. Cisplatin nephrotoxicity: mechanisms and renoprotective strategies. Kidney Int. [Internet]. 2008;73:994-1007. Available from: http://dx.doi.org/10.1038/sj.ki.5002786.

[54] Luque Y, Louis K, Jouanneau C, et al. Vancomycin-associated cast nephropathy. J. Am. Soc. Nephrol. [Internet]. 2017;28:1723-1728. Available from: http://www.jasn.org/lookup/doi/10.1681/ASN.2016080867. 
[55] Chevalier RL. Growth factors and apoptosis in neonatal ureteral obstruction. J. Am. Soc. Nephrol. [Internet]. 1996;7:1098-1105. Available from: http://www.ncbi.nlm.nih.gov/pubmed/8866400.

[56] Neuhoff S, Gaohua L, Burt H, et al. Accounting for transporters in renal clearance: towards a mechanistic kidney model (Mech KiM). In: Sugiyama Y, Steffansen B, editors. Transporters in drug development: discovery, optimization, clinical study and regulation. [Internet]. New York, USA: Springer; 2013. p. 155-177. Available from: http://link.springer.com/10.1007/9781-4614-8229-1_7. * Sophisticated mechanistic modelling tool

[57] Schetz M, Dasta J, Goldstein S, et al. Drug-induced acute kidney injury. Curr. Opin. Crit. Care [Internet]. 2005;11:555-565. Available from:

http://content.wkhealth.com/linkback/openurl?sid=WKPTLP:landingpage\&an=00012995200708000-00001.

[58] Wenzel RR. Renal protection in hypertensive patients: selection of antihypertensive therapy. Drugs [Internet]. 2005;65 Suppl 2:29-39. Available from: http://www.ncbi.nlm.nih.gov/pubmed/16398060.

[59] Remuzzi G. Renoprotective effect of ACE inhibitors: dissecting the molecular clues and expanding the blood pressure goal. Am. J. Kidney Dis. 1999;34:951-954.

[60] Casas JP, Chua W, Loukogeorgakis S, et al. Effect of inhibitors of the renin-angiotensin system and other antihypertensive drugs on renal outcomes: systematic review and meta-analysis. Lancet. 2005;366:2026-2033.

[61] Hsu T-W, Liu J-S, Hung S-C, et al. Renoprotective effect of renin-angiotensin-aldosterone system blockade in patients with predialysis advanced chronic kidney disease, hypertension, and anemia. JAMA Intern. Med. [Internet]. 2014;174:347-354. Available from: http://archinte.jamanetwork.com/article.aspx?doi=10.1001/jamainternmed.2013.12700.

[62] Wu L-S, Chang S-H, Chang G-J, et al. A comparison between angiotensin converting enzyme inhibitors and angiotensin receptor blockers on end stage renal disease and major adverse cardiovascular events in diabetic patients: a population-based dynamic cohort study in Taiwan. Cardiovasc. Diabetol. [Internet]. 2016;15:56. Available from: http://cardiab.biomedcentral.com/articles/10.1186/s12933-016-0365-x.

[63] Onuigbo MAC. Can ACE inhibitors and angiotensin receptor blockers be detrimental in CKD patients? Nephron - Clin. Pract. 2011;118:407-419.

[64] Anand S, Tamura MK. Combining angiotensin receptor blockers with ACE inhibitors in elderly patients. Am. J. Kidney Dis. [Internet]. 2012;59:11-14. Available from: http://linkinghub.elsevier.com/retrieve/pii/S0272638611013217. 
[65] Navis G, Faber HJ, de Zeeuw D, et al. ACE inhibitors and the kidney. A risk-benefit assessment. Drug Saf. [Internet]. 1996;15:200-211. Available from:

http://www.ncbi.nlm.nih.gov/pubmed/8879974.

[66] Goldfarb DA, Diz DI, Tubbs RR, et al. Angiotensin II receptor subtypes in the human renal cortex and renal cell carcinoma. J. Urol. [Internet]. 1994;151:208-213. Available from: http://www.ncbi.nlm.nih.gov/pubmed/8254815.

[67] de Gasparo M, Levens NR. Pharmacology of angiotensin II receptors in the kidney. Kidney Int. [Internet]. 1994;46:1486-1491. Available from:

http://www.ncbi.nlm.nih.gov/pubmed/7699986.

[68] Zhuo J, Dean R, MacGregor D, et al. Presence of angiotensin II AT2 receptor binding sites in the adventitia of human kidney vasculature. Clin. Exp. Pharmacol. Physiol. Suppl. [Internet]. 1996;3:S147-S154. Available from: http://www.ncbi.nlm.nih.gov/pubmed/8993855.

[69] Siragy HM. The angiotensin II type 2 receptor and the kidney. J. Renin-AngiotensinAldosterone Syst. 2010;11:33-36.

[70] Carey RM, Padia SH. Role of angiotensin AT2 receptors in natriuresis: Intrarenal mechanisms and therapeutic potential. Clin. Exp. Pharmacol. Physiol. 2013;40:527-534.

[71] Loboz KK, Shenfield GM. Drug combinations and impaired renal function- the 'triple whammy.' Br. J. Clin. Pharmacol. [Internet]. 2005;59:239-243. Available from: 10.1111/j.03065251.2004.2188.x\%5Cnhttp://ezproxy.think.edu.au/login?url=http://search.ebscohost.com/I ogin.aspx?direct=true\&db=aph\&AN=15806756\&site=ehostlive \&scope=site \&custid=ns 195171 .

[72] Gambaro G, Perazella MA. Adverse renal effects of anti-inflammatory agents: evaluation of selective and nonselective cyclooxygenase inhibitors. J. Intern. Med. [Internet]. 2003;253:643-652. Available from: http://www.ncbi.nlm.nih.gov/pubmed/12755960.

[73] Whelton A. Renal aspects of treatment with conventional nonsteroidal anti-inflammatory drugs versus cyclooxygenase-2-specific inhibitors. Am. J. Med. 2001;110:33S-42S.

[74] Klaassen CD, editor. Casarett and Doull's toxicology: the basic science of poisons [Internet]. Seventh. New York, USA: McGraw-Hill Medical; 2008. Available from: http://www.loc.gov/catdir/enhancements/fy0726/2007015656-b.html.

[75] Markowitz GS, Perazella MA. Drug-induced renal failure: a focus on tubulointerstitial disease. Clin. Chim. Acta. 2005;351:31-47.

[76] Perazella MA. Toxic nephropathies: core curriculum 2010. Am. J. Kidney Dis. [Internet]. 2010;55:399-409. Available from: http://dx.doi.org/10.1053/j.ajkd.2009.10.046. 
[77] Lopez-Novoa JM, Quiros Y, Vicente L, et al. New insights into the mechanism of aminoglycoside nephrotoxicity: an integrative point of view. Kidney Int. [Internet]. 2011;79:33-45. Available from: http://linkinghub.elsevier.com/retrieve/pii/S0085253815546760.

[78] Ozbek E. Induction of oxidative stress in kidney. Int. J. Nephrol. 2012;2012:Article ID 465897.

[79] Kröning R, Katz D, Lichtenstein AK, et al. Differential effects of cisplatin in proximal and distal renal tubule epithelial cell lines. Br. J. Cancer [Internet]. 1999;79:293-299. Available from: http://www.nature.com/doifinder/10.1038/sj.bjc.6990047.

[80] Baley JE, Meyers C, Kliegman RM, et al. Pharmacokinetics, outcome of treatment, and toxic effects of amphotericin B and 5-fluorocytosine in neonates. J. Pediatr. 1990;116:791-797.

[81] Ravnskov U. Glomerular, tubular and interstitial nephritis associated with non-steroidal antiinflammatory drugs. Evidence of a common mechanism. Br. J. Clin. Pharmacol. 1999;47:203-210.

[82] Cameron JS. Tubular and interstitial factors in the progression of glomerulonephritis. Pediatr. Nephrol. [Internet]. 1992;6:292-303. Available from: http://www.ncbi.nlm.nih.gov/pubmed/1616844.

[83] Rossert J. Drug-induced acute interstitial nephritis. Kidney Int. 2001;60:804-817.

[84] Greim H. The kidney and urinary tract. In: Greim H, Snyder R, editors. Toxicology and risk assessment: a comprehensive introduction. Chichester, UK: John Wiley \& Sons, Ltd.; 2008. p. 295-304.

[85] Gharavi AG, Yan Y, Scolari F, et al. IgA nephropathy, the most common cause of glomerulonephritis, is linked to 6q22-23. Nat. Genet. 2000;26:354-357.

[86] Mulay SR, Anders H-J. Crystal nephropathies: mechanisms of crystal-induced kidney injury. Nat. Rev. Nephrol. [Internet]. 2017;13:226-240. Available from: http://dx.doi.org/10.1038/nrneph.2017.10.

[87] Perazella MA. Crystal-induced acute renal failure. Am. J. Med. [Internet]. 1999;106:459-465. Available from: http://linkinghub.elsevier.com/retrieve/pii/S0002934399000418.

[88] Herlitz LC, D’Agati VD, Markowitz GS. Crystalline nephropathies. Arch. Pathol. Lab. Med. 2012;136:713-720.

[89] Baxter Healthcare Corporation. Vancomycin injection, USP, for intravenous use only, prescribing information [Internet]. 2015 [cited 2018 Mar 7]. Available from: https://www.accessdata.fda.gov/drugsatfda_docs/label/2015/050671s022lbl.pdf.

[90] Zager RA. Rhabdomyolysis and myohemoglobinuric acute renal failure. Kidney Int. [Internet]. 1996;49:314-326. Available from: 
http://linkinghub.elsevier.com/retrieve/pii/S0085253815593423.

[91] Huerta-Alardín AL, Varon J, Marik PE. Bench-to-bedside review: rhabdomyolysis - an overview for clinicians. Crit. Care [Internet]. 2005;9:158-169. Available from:

http://www.pubmedcentral.nih.gov/articlerender.fcgi?artid=1175909\&tool=pmcentrez\&ren dertype=abstract.

[92] Ruggenenti P, Noris M, Remuzzi G. Thrombotic microangiopathy, hemolytic uremic syndrome, and thrombotic thrombocytopenic purpura. Kidney Int. 2001;60:831-846.

[93] Tsai H-M. The kidney in thrombotic thrombocytopenic purpura. Minerva Med. [Internet]. 2007;98:731-747. Available from:

http://www.ncbi.nlm.nih.gov/pubmed/18299685?dopt=abstract.

[94] Manor SM, Guillory GS, Jain SP. Clopidogrel-induced thrombotic thrombocytopenic purpurahemolytic uremic syndrome after coronary artery stenting. Pharmacotherapy [Internet]. 2004;24:664-667. Available from:

http://www.ncbi.nlm.nih.gov/entrez/query.fcgi?cmd=Retrieve\&db=PubMed\&dopt=Citation\& list_uids=15162901.

[95] Al-Nouri ZL, Reese JA, Terrell DR, et al. Drug-induced thrombotic microangiopathy: a systematic review of published reports. Blood. 2015;125:616-618.

[96] Pisoni R, Ruggenenti P, Remuzzi G. Drug-induced thrombotic microangiopathy: incidence, prevention and management. Drug Saf. 2001;24:491-501.

[97] El Karoui K, Hill GS, Karras A, et al. A clinicopathologic study of thrombotic microangiopathy in IgA nephropathy. J. Am. Soc. Nephrol. [Internet]. 2012;23:137-148. Available from: http://www.jasn.org/cgi/doi/10.1681/ASN.2010111130.

[98] Gwinner W, Gröne H-J. Role of reactive oxygen species in glomerulonephritis. Nephrol. Dial. Transplant. 2000;15:1127-1132.

[99] Barratt M. A quantitative structure-activity relationship (QSAR) for prediction of alpha(2mu)globulin nephropathy. Toxicol. Vitr. 1994;8:885-887.

[100] Vadivel N, Trikudanathan S, Singh AK. Analgesic nephropathy. Kidney Int. [Internet]. 2007;72:517-520. Available from: http://dx.doi.org/10.1038/sj.ki.5002251.

[101] Mohrmann M, Ansorge S, Schmich U, et al. Toxicity of ifosfamide, cyclophosphamide and their metabolites in renal tubular cells in culture. Pediatr. Nephrol. [Internet]. 1994;8:157163. Available from: http://www.ncbi.nlm.nih.gov/pubmed/7517170.

[102] Batista CKLP, Brito GAC, Souza MLP, et al. A model of hemorrhagic cystitis induced with acrolein in mice. Brazilian J. Med. Biol. Res. 2006;39:1475-1481.

[103] Korkmaz A, Topal T, Oter S. Pathophysiological aspects of cyclophosphamide and ifosfamide 
induced hemorrhagic cystitis; implication of reactive oxygen and nitrogen species as well as PARP activation. Cell Biol. Toxicol. [Internet]. 2007;23:303-312. Available from: http://link.springer.com/10.1007/s10565-006-0078-0.

[104] Mills KA. Cyclophosphamide and ifosfamide: mechanisms of cytotoxic action and consequences for normal bladder function [dissertation]. Robina (QLD, Australia): Bond University; 2015.

[105] Bostom AG, Kronenberg F, Ritz E. Predictive performance of renal function equations for patients with chronic kidney disease and normal serum creatinine levels. J. Am. Soc. Nephrol. [Internet]. 2002;13:2140-2144. Available from: http://www.jasn.org/cgi/doi/10.1097/01.ASN.0000022011.35035.F3.

[106] Kim SY, Moon A. Drug-induced nephrotoxicity and its biomarkers. Biomol. Ther. 2012;20:268272.

[107] Hüttenhofer A, Mayer G. Circulating miRNAs as biomarkers of kidney disease. Clin. Kidney J. 2017;10:27-29.

[108] Klimisch H-J, Andreae M, Tillmann U. A systematic approach for evaluating the quality of experimental toxicological and ecotoxicological data. Regul. Toxicol. Pharmacol. 1997;25:1-5.

[109] Dearden JC. In silico prediction of ADMET properties: how far have we come? Expert Opin. Drug Metab. Toxicol. [Internet]. 2007;3:635-639. Available from: http://www.tandfonline.com/doi/full/10.1517/17425255.3.5.635.

[110] Nendza M, Aldenberg T, Benfenati E, et al. Chapter 4. Data quality assessment for in silico methods: a survey of approaches and needs. In: Cronin MTD, Madden JC, editors. In silico toxicology: principles and applications. [Internet]. Cambridge, UK: RSC Publishing; 2010. p. 59-117. Available from: http://ebook.rsc.org/?DOI=10.1039/9781849732093-00059.

[111] Przybylak KR, Madden JC, Cronin MTD, et al. Assessing toxicological data quality: basic principles, existing schemes and current limitations. SAR QSAR Environ. Res. 2012;23:435459.

[112] Madden JC. Chapter 5. Sources of chemical information, toxicity data and assessment of their quality. In: Cronin MT, Madden JC, Enoch SJ, et al., editors. Chemical toxicity prediction: category formation and read-across [Internet]. Cambridge, UK: RSC Publishing; 2013. p. 98126. Available from: http://ebook.rsc.org/?DOI=10.1039/9781849734400-00098.

[113] Przybylak KR, Madden JC, Covey-Crump E, et al. Characterisation of data resources for in silico modelling: benchmark datasets for ADME properties. Expert Opin. Drug Metab. Toxicol. [Internet]. 2017;1-13. Available from: http://dx.doi.org/10.1080/17425255.2017.1316449.

[114] World Health Organization (WHO). IPCS Environmental Health Criteria 119: principles and 
methods for the assessment of nephrotoxicity associated with exposure to chemicals [Internet]. Geneva; 1991 [cited 2018 Jan 25]. Available from: http://www.inchem.org/documents/ehc/ehc/ehc119.htm.

[115] ICH. ICH Harmonized Tripartite Guideline "Safety Pharmacology Studies For Human Pharmaceuticals S7A" [Internet]. International Conference on Harmonisation of Technical Requirements for Registration of Pharmaceuticals for Human Use. 2000 [cited 2018 Jan 25]. Available from:

http://www.ich.org/fileadmin/Public_Web_Site/ICH_Products/Guidelines/Safety/S7A/Step4/ S7A_Guideline.pdf.

[116] Singh NP, Ganguli A, Prakash A. Drug-induced kidney diseases. J. Assoc. Physicians India. 2003;51:970-979.

[117] Neyra JA, Alvarez-Maza JC, Novak JE. Anuric acute kidney injury induced by acute mountain sickness prophylaxis with acetazolamide. J. Investig. Med. High Impact Case Reports [Internet]. 2014;2:1-5. Available from: http://www.ncbi.nlm.nih.gov/pubmed/25264540\%0Ahttp://www.pubmedcentral.nih.gov/art iclerender.fcgi?artid=PMC4175968.

[118] MN-AM. COSMOS Database. Exported combined (COSMOS and Munro) data set [Internet]. Molecular Networks GmbH, Germany. Altamira, LLC, USA. 2018 [cited 2018 May 1]. Available from: https://cosmosdb.eu/cosmosdb.v2/accounts/login/?next=/cosmosdb.v2/.

[119] Izzedine H, Launay-Vacher V, Deray G. Antiviral drug-induced nephrotoxicity. Am. J. Kidney Dis. $2005 ; 45: 804-817$.

[120] Lin Z, Will Y. Evaluation of drugs with specific organ toxicities in organ-specific cell lines. Toxicol. Sci. 2012;126:114-127.

[121] Pazhayattil GS, Shirali AC. Drug-induced impairment of renal function. Int. J. Nephrol. Renovasc. Dis. 2014;7:457-468.

[122] Khan FY. Rhabdomyolysis: a review of the literature. Neth. J. Med. 2009;67:272-283.

[123] Evenepoel P. Toxic acute renal failure. In: Ronco C, Bellomo R, Kellum JA, editors. Critical care nephrology. Second. Philadelphia, USA: Saunders/Elsevier; 2009. p. 168-171.

[124] Racusen LC, Solez K. Nephrotoxic tubular and interstitial lesions: morphology and classification. Toxicol. Pathol. 1986;14:45-57.

[125] Tune BM. The renal toxicity of beta-lactam antibiotics: mechanisms and clinical implications. In: De Broe ME, Porter GA, Bennett WM, et al., editors. Clinical nephrotoxins [Internet]. Dordrecht: Springer Netherlands; 1998. p. 121-134. Available from: http://link.springer.com/10.1007/978-94-015-9088-4_8. 
[126] U.S. Environmental Protection Agency (EPA). Animal toxicity studies: effects and endpoints (Toxicity Reference Database - ToxRefDB files), data release October 2014 [Internet]. 2014 [cited 2017 Nov 28]. Available from: https://www.epa.gov/chemical-research/toxicityforecaster-toxcasttm-data.

[127] Maschio G, Alberti D, Janin G, et al. Effect of the angiotensin-converting-enzyme inhibitor benazepril on the progression of chronic renal insufficiency. N. Engl. J. Med. [Internet]. 1996;334:939-945. Available from:

http://ovidsp.ovid.com/ovidweb.cgi?T=JS\&PAGE=reference\&D=emed4\&NEWS=N\&AN=19980 45211.

[128] Latcha S. Chapter 12: Pharmacokinetics of chemotherapeutic agents in kidney disease. Onconephrology curriculum. American Society of Nephrology [Internet]. 2016 [cited 2018 Mar 8]. Available from: https://www.asnonline.org/education/distancelearning/curricula/onco/Chapter12.pdf.

[129] Choudhury D, Ahmed Z. Drug-associated renal dysfunction and injury. Nat. Clin. Pract. Nephrol. 2006;2:80-91.

[130] Whelton A, Schulman G, Wallemark C, et al. Effects of celecoxib and naproxen on renal function in the elderly. Arch. Intern. Med. [Internet]. 2000;160:1465-1470. Available from: http://archinte.jamanetwork.com/article.aspx?doi=10.1001/archinte.160.10.1465.

[131] Tune BM. Nephrotoxicity of beta-lactam antibiotics: mechanisms and strategies for prevention. Pediatr. Nephrol. 1997;11:768-772.

[132] Barza M. The nephrotoxicity of cephalosporins: an overview. J. Infect. Dis. [Internet]. 1978;137:S60-S73. Available from: http://www.jstor.org/stable/30108956.

[133] Lieberthal W. Models of toxic acute renal failure. In: Ronco C, Bellomo R, Kellum JA, editors. Critical care nephrology. 2nd ed. Philadelphia, USA: Saunders/Elsevier; 2009. p. 228-233.

[134] Fang C, Behr M, Xie F, et al. Mechanism of chloroform-induced renal toxicity: noninvolvement of hepatic cytochrome P450-dependent metabolism. Toxicol. Appl. Pharmacol. 2008;227:48-55.

[135] Liu S, Yao Y, Lu S, et al. The role of renal proximal tubule P450 enzymes in chloroform-induced nephrotoxicity: utility of renal specific $\mathrm{P} 450$ reductase knockout mouse models. Toxicol. Appl. Pharmacol. [Internet]. 2013;272:230-237. Available from: http://linkinghub.elsevier.com/retrieve/pii/S0041008X13002512.

[136] Bird ST, Etminan M, Brophy JM, et al. Risk of acute kidney injury associated with the use of fluoroquinolones. Can. Med. Assoc. J. [Internet]. 2013;185:E475-482. Available from: http://www.pubmedcentral.nih.gov/articlerender.fcgi?artid=3708027\&tool=pmcentrez\&ren 
dertype=abstract.

[137] Ma TK-W, Chow K-M, Choy ASM, et al. Clinical manifestation of macrolide antibiotic toxicity in CKD and dialysis patients. Clin. Kidney J. 2014;7:507-512.

[138] Berg KJ. Nephrotoxicity related to contrast media. Scand. J. Urol. Nephrol. 2000;34:317-322.

[139] Ling W, Zhaohui N, Ben H, et al. Urinary IL-18 and NGAL as early predictive biomarkers in contrast-induced nephropathy after coronary angiography. Nephron Clin. Pract. [Internet]. 2008;108:c176-c181. Available from: https://www.karger.com/Article/FullText/117814.

[140] Smith GA, Damon LE, Rugo HS, et al. High-dose cytarabine dose modification reduces the incidence of neurotoxicity in patients with renal insufficiency. J. Clin. Oncol. [Internet]. 1997;15:833-839. Available from: http://ascopubs.org/doi/10.1200/JCO.1997.15.2.833.

[141] Rosenberg LE, Hayslett JP. Nephrotoxic effects of penicillamine in cystinuria. JAMA. 1967;201:698-699.

[142] Janssen van Doorn K, Van der Niepen P, van Tussenbroeck F, et al. Acute tubulo-interstitial nephritis and renal infarction secondary to ergotamine therapy. Nephrol. Dial. Transplant. 2000;15:1877-1879.

[143] Aronson JK, editor. Meyler's side effects of drugs: the international encyclopedia of adverse drug reactions and interactions. 16th ed. Amsterdam: Elsevier Science; 2016.

[144] Carmichael J, Shankel SW. Effects of nonsteroidal anti-inflammatory drugs on prostaglandins and renal function. Am. J. Med. 1985;78:992-1000.

[145] Musu M, Finco G, Antonucci R, et al. Acute nephrotoxicity of NSAID from the foetus to the adult. Eur. Rev. Med. Pharmacol. Sci. 2011;15:1461-1472.

[146] Henrich WL. Nephrotoxicity of nonsteroidal anti-inflammatory agents. Am. J. Kidney Dis. [Internet]. 1983;2:478-484. Available from: http://dx.doi.org/10.1016/S0272-6386(83)800833.

[147] Lameire N. Nephrotoxicity of recent anti-cancer agents. Clin. Kidney J. 2014;7:11-22.

[148] Glezerman IG, Kris MG, Miller V, et al. Gemcitabine nephrotoxicity and hemolytic uremic syndrome: report of 29 cases from a single institution. Clin. Nephrol. [Internet]. 2009;71:130139. Available from: http://www.ncbi.nlm.nih.gov/pubmed/19203505.

[149] Eshraghi-Jazi F, Talebi A, Sadat Mirsaeedi F, et al. Gentamicin induced nephrotoxicity: the role of sex hormones in gonadectomized male and female rats. Scientifica (Cairo). 2016;2016:article ID 5025097.

[150] Vydrin AF, Shikhaleev IV, Makhortov VL, et al. Component composition of gentamicin sulfate preparations. Pharm. Chem. J. 2003;37:448-450.

[151] Magil AB, Ballon HS, Cameron EC, et al. Acute interstitial nephritis associated with thiazide 
diuretics. Clinical and pathologic observations in three cases. Am. J. Med. 1980;69:939-943.

[152] Tencer J, Bakoush O, Torffvit O. Diagnostic and prognostic significance of proteinuria selectivity index in glomerular diseases. Clin. Chim. Acta. 2000;297:73-83.

[153] Merck \& Co. Inc. Product information INTRON ${ }^{\circledR}$ A, interferon alfa-2b, recombinant. For injection [Internet]. 2016 [cited 2018 Mar 2]. p. 1-39. Available from: https://www.merck.com/product/usa/pi_circulars/i/intron_a/intron_a_pi.pdf.

[154] Brewster UC, Perazella MA. Proton pump inhibitors and the kidney: critical review. Clin. Nephrol. [Internet]. 2007;68:65-72. Available from:

http://www.embase.com/search/results?subaction=viewrecord\&from=export\&id=L4724395 0.

[155] Shah PR, Kute VB, Gumber MR, et al. Benzene hexachloride poisoning with rhabdomyolysis and acute kidney injury. Indian J. Nephrol. 2013;23:80-81.

[156] World M, Stevens P, Ashton M, et al. Mesalazine-associated interstitial nephritis. Nephrol. Dial. Transplant. 1996;11:614-621.

[157] Oikonomou KA, Kapsoritakis AN, Stefanidis I, et al. Drug-induced nephrotoxicity in inflammatory bowel disease. Nephron Clin. Pract. 2011;119:c89-c96.

[158] Kovacevic L, Bernstein J, Valentini RP, et al. Renal papillary necrosis induced by naproxen. Pediatr. Nephrol. 2003;18:826-829.

[159] Hörl WH. Nonsteroidal anti-inflammatory drugs and the kidney. Pharmaceuticals. 2010;3:2291-2321.

[160] Oplinger $M$, Andrews $C O$. Nitrofurantoin contraindication in patients with a creatinine clearance below $60 \mathrm{~mL} / \mathrm{min}$ : looking for the evidence. Ann. Pharmacother. 2013;47:106-111.

[161] Simpson IJ, Marshall MR, Pilmore H, et al. Proton pump inhibitors and acute interstitial nephritis: report and analysis of 15 cases. Nephrology. 2006;11:381-385.

[162] Novartis Pharmaceuticals Corporation. AREDIA - pamidronate disodium injection, powder, lyophilized, for solution, prescribing information [Internet]. 2008 [cited 2018 Mar 7]. Available from: https://www.accessdata.fda.gov/drugsatfda_docs/label/2008/020036s035lbl.pdf.

[163] Weng $\mathrm{C}-\mathrm{H}$, Chen $\mathrm{H}-\mathrm{H}$, Hu C-C, et al. Predictors of acute kidney injury after paraquat intoxication. Oncotarget [Internet]. 2017;8:51345-51354. Available from: http://www.ncbi.nlm.nih.gov/pubmed/28591706\%5Cnhttp://www.oncotarget.com/fulltext/ 17975.

[164] APP Pharmaceuticals LLC. PENTAM 300 - pentamidine isethionate injection, powder, lyophilized, for solution, prescribing information [Internet]. 2012 [cited 2018 Mar 7]. 
Available from: https://dailymed.nIm.nih.gov/dailymed/drugInfo.cfm?setid=cc2b635e-48404dc3-a177-5484371680e8.

[165] Glezerman IG. Drug nephropathies. In: Finkel KW, Howard SC, editors. Renal disease in cancer patients [Internet]. Boston, USA: Academic Press/Elsevier; 2014. p. 195-208. Available from: http://dx.doi.org/10.1016/B978-0-12-415948-8.00013-1.

[166] Morin JP, Thomas N, Toutain H, et al. Modulation of gentamicin nephrotoxicity by chronic inhibition of angiotensin-I-converting enzyme in rat. Arch. Toxicol. [Internet]. 1989 [cited 2018 Apr 23];63:47-53. Available from: http://link.springer.com/10.1007/BF00334634.

[167] Waddington F, Naunton M, Thomas J. Paracetamol and analgesic nephropathy: Are you kidneying me? Int. Med. Case Rep. J. 2015;8:1-5.

[168] Eyanagi R, Shigematsu H, Yoshida K, et al. Metabolism and nephrotoxicity of phenacetin and sulfanilamide. J. Pharmacobiodyn. [Internet]. 1985;8:95-105. Available from: http://joi.jlc.jst.go.jp/JST.Journalarchive/bpb1978/8.95?from=CrossRef.

[169] Maiche AG, Lappalainen K, Teerenhovi L. Renal insufficiency in patients treated with high dose methotrexate. Acta Oncol. (Madr). 1988;27:73-74.

[170] Endre ZH, Pickering JW, Walker RJ. Clearance and beyond: the complementary roles of GFR measurement and injury biomarkers in acute kidney injury (AKI). Am. J. Physiol. Renal Physiol. [Internet]. 2011;301:F697-707. Available from: https://www.physiology.org/doi/pdf/10.1152/ajprenal.00448.2010.

[171] Epstein M, Oster JR. Beta blockers and renal function: a reappraisal. J. Clin. Hypertens. [Internet]. 1985;1:85-99. Available from: http://www.ncbi.nlm.nih.gov/pubmed/2873206.

[172] Mendes CAC, Burdmann EA. Polymyxins - review with emphasis on nephrotoxicity. Rev. Assoc. Med. Bras. 2009;55:752-759.

[173] Ozkan G, Ulusoy S, Orem A, et al. How does colistin-induced nephropathy develop and can it be treated? Antimicrob. Agents Chemother. 2013;57:3463-3469.

[174] Moreno-Manzano V, Mampaso F, Sepúlveda-Muñoz JC, et al. Retinoids as a potential treatment for experimental puromycin-induced nephrosis. Br. J. Pharmacol. 2003;139:823831.

[175] Löwenborg EKM, Jaremko G, Berg UB. Glomerular function and morphology in puromycin aminonucleoside nephropathy in rats. Nephrol. Dial. Transplant. 2000;15:1547-1555.

[176] IPCS INCHEM. Quinidine [Internet]. 1990 [cited 2017 Mar 8]. Available from: http://www.inchem.org/documents/pims/pharm/quinidin.htm.

[177] Ingrasciotta $Y$, Sultana J, Giorgianni F, et al. The burden of nephrotoxic drug prescriptions in patients with chronic kidney disease: a retrospective population-based study in Southern 
Italy. PLoS One. 2014;9:e89072, 1-8.

[178] Hobbs SD, Claridge MW, Wilmink ABM, et al. Effect of ramipril on renal function in patients with intermittent claudication. Vasc. Health Risk Manag. 2008;4:471-475.

[179] GlaxoSmithKline. ZANTAC ${ }^{\circledR}$, ranitidine hydrochloride and ranitidine hydrochloride effervescent, prescribing information [Internet]. 2004 [cited 2018 Mar 7]. Available from: http://us.gsk.com/products/assets/us_zantac.pdf.

[180] Sanofi-Aventis U.S. LLC. RIFADIN ${ }^{\circledR}$ (rifampin capsules USP) and RIFADIN ${ }^{\circledR}$ IV (rifampin for injection USP), prescribing information [Internet]. 2017 [cited 2018 Mar 7]. Available from: http://products.sanofi.us/rifadin/rifadin.pdf.

[181] Fernandez-Fernandez B, Montoya-Ferrer A, Sanz AB, et al. Tenofovir nephrotoxicity: 2011 update. AIDS Res. Treat. 2011;2011:article ID 354908.

[182] Andreucci M, Faga T, Andreucci VE. Acute interstitial nephritis. In: Ronco C, Bellomo R, Kellum JA, editors. Critical care nephrology. 2nd ed. Philadelphia, PA: Saunders/Elsevier; 2009. p. 355-357.

[183] U.S. Food and Drug Administration (FDA). TOLECTIN DS (tolmetin sodium) capsules, medication guide [Internet]. 2007 [cited 2018 Mar 7]. Available from: https://www.accessdata.fda.gov/drugsatfda_docs/label/2008/018084s052,017628s068lbl.pd f.

[184] National Research Council. Assessing the human health risks of trichloroethylene: key scientific issues [Internet]. Washington, D.C., USA: National Academies Press; 2006. Available from: http://www.nap.edu/catalog/11707.

[185] Fraser TN, Avellaneda AA, Graviss EA, et al. Acute kidney injury associated with trimethoprim/sulfamethoxazole. J. Antimicrob. Chemother. 2012;67:1271-1277.

[186] Kitano A, Motohashi H, Takayama A, et al. Valacyclovir-induced acute kidney injury in Japanese patients based on the PMDA adverse drug reactions reporting database. Ther. Innov. Regul. Sci. 2015;49:81-85.

[187] Perry CM, Faulds D. Valaciclovir. A review of its antiviral activity, pharmacokinetic properties and therapeutic efficacy in herpesvirus infections. Drugs [Internet]. 1996;52:754-772. Available from: http://download.springer.com/static/pdf/57/art\%253A10.2165\%252F00003495-19965205000009.pdf?auth66=1422025222_b2eaf06648894607e752334168578004\&ext=.pdf.

[188] Novartis Pharmaceuticals Corporation. ZOMETA ${ }^{\circledR}$ (zoledronic acid) injection, prescribing information [Internet]. 2014 [cited 2018 Mar 7]. Available from: https://www.accessdata.fda.gov/drugsatfda_docs/label/2014/021223s028lbl.pdf. 
[189] U.S. National Library of Medicine (NLM). ChemIDplus Advanced: A TOXNET database [Internet]. 2017 [cited 2017 Dec 19]. Available from: https://chem.nlm.nih.gov/chemidplus/.

[190] U.S. National Library of Medicine (NLM). TOXNET Home, Frequently Asked Questions [Internet]. 2017 [cited 2017 Dec 19]. Available from: https://toxnet.nlm.nih.gov/newtoxnet/faq.html.

[191] U.S. National Library of Medicine (NLM). Fact Sheet TOXNET ${ }^{\oplus}$ : Toxicology Data Network [Internet]. 2017 [cited 2017 Dec 19]. Available from: https://www.nlm.nih.gov/pubs/factsheets/toxnetfs.html.

[192] U.S. Environmental Protection Agency (EPA). Chemistry Dashboard [Internet]. 2017 [cited 2018 Feb 28]. Available from: https://comptox.epa.gov/dashboard/.

[193] Bento AP, Gaulton A, Hersey A, et al. The ChEMBL bioactivity database: an update. Nucleic Acids Res. 2014;42:1083-1090.

[194] EMBL-EBI. ChEMBL database Home [Internet]. 2017 [cited 2017 Dec 19]. Available from: https://www.ebi.ac.uk/chembl/.

[195] Wishart DS, Feunang YD, Guo AC, et al. DrugBank 5.0: a major update to the DrugBank database for 2018. Nucleic Acids Res. 2018;46:D1074-D1082.

[196] Drugbank [Internet]. 2018 [cited 2018 Jun 8]. Available from: https://www.drugbank.ca/.

[197] Chambers J, Davies M, Gaulton A, et al. UniChem: a unified chemical structure crossreferencing and identifier tracking system. J. Cheminform. [Internet]. 2013;5:1-9. Available from: Journal of Cheminformatics.

[198] EMBL-EBI. UniChem [Internet]. 2017 [cited 2018 Feb 28]. Available from: https://www.ebi.ac.uk/unichem/.

[199] Kim S, Thiessen PA, Bolton EE, et al. PubChem Substance and Compound databases. Nucleic Acids Res. [Internet]. 2016;44:D1202-D1213. Available from:

https://academic.oup.com/nar/article-lookup/doi/10.1093/nar/gkv951.

[200] National Center for Biotechnology Information. U.S. National Library of Medicine. PubChem [Internet]. 2018 [cited 2018 Jun 7]. Available from: https://pubchem.ncbi.nlm.nih.gov/search/.

[201] Sushko I, Novotarskyi S, Körner R, et al. Online chemical modeling environment (OCHEM): web platform for data storage, model development and publishing of chemical information. J. Comput. Aided. Mol. Des. 2011;25:533-554.

[202] Online chemical database with modelling environment [Internet]. [cited 2018 Sep 17]. Available from: https://ochem.eu/home/show.do.

[203] Zhang Q, Yang B, Chen X, et al. Renal Gene Expression Database (RGED): a relational database 
of gene expression profiles in kidney disease. Database. 2014;2014:1-6.

[204] RGED - Renal Gene Expression Database [Internet]. 2014 [cited 2018 Jun 7]. Available from: http://rged.wall-eva.net/.

[205] The University of Michigan. Nephroseq ${ }^{\mathrm{TM}}$ [Internet]. 2018 [cited 2018 Jan 25]. Available from: https://www.nephroseq.org/resource/login.html.

[206] HKUPP. Human Kidney \& Urine Proteome Project [Internet]. 2007 [cited 2018 Jan 25]. Available from: http://www.hkupp.org/index.htm.

[207] Husi H, Barr JB, Skipworth RJE, et al. The Human Urinary Proteome Fingerprint Database UPdb. Int. J. Proteomics [Internet]. 2013;2013:article ID 760208, 1-7. Available from: http://www.hindawi.com/journals/ijpro/2013/760208/.

[208] UPdb - Urinary Peptidomics and Peak-maps [Internet]. 2014 [cited 2018 Sep 17]. Available from: http://www.padb.org/updb/.

[209] Zhai R, Su S, Lu X, et al. Proteomic profiling in the sera of workers occupationally exposed to arsenic and lead: Identification of potential biomarkers. BioMetals. 2005;18:603-613.

[210] Neuhoff N v., Kaiser T, Wittke S, et al. Mass spectrometry for the detection of differentially expressed proteins: a comparison of surface-enhanced laser desorption/ionization and capillary electrophoresis/mass spectrometry. Rapid Commun. Mass Spectrom. 2004;18:149156.

[211] Haubitz $M$, Wittke $S$, Weissinger EM, et al. Urine protein patterns can serve as diagnostic tools in patients with IgA nephropathy. Kidney Int. 2005;67:2313-2320.

[212] Wittke S, Fliser D, Haubitz M, et al. Determination of peptides and proteins in human urine with capillary electrophoresis-mass spectrometry, a suitable tool for the establishment of new diagnostic markers. J. Chromatogr. A [Internet]. 2003;1013:173-181. Available from: https://www.sciencedirect.com/science/article/pii/S0021967303007131?via\%3Dihub.

[213] Weissinger EM, Wittke S, Kaiser T, et al. Proteomic patterns established with capillary electrophoresis and mass spectrometry for diagnostic purposes. Kidney Int. [Internet]. 2004;65:2426-2434. Available from:

https://www.sciencedirect.com/science/article/pii/S0085253815499880?via\%3Dihub.

[214] Jupp S, Klein J, Schanstra J, et al. Developing a kidney and urinary pathway knowledge base. J. Biomed. Semantics [Internet]. 2011;2:S7. Available from: http://www.jbiomedsem.com/content/2/S2/S7.

[215] KUPKB - The Kidney \& Urinary Pathway Knowledge Base [Internet]. 2014 [cited 2018 Sep 17]. Available from: http://www.kupkb.org/\#tab0.

[216] Davis AP, Grondin CJ, Johnson RJ, et al. The Comparative Toxicogenomics Database: update 
2017. Nucleic Acids Res. 2017;45:D972-D978.

[217] North Carolina State University. ctd - Comparative Toxicogenomics Database [Internet]. 2018 [cited 2018 Sep 17]. Available from: http://ctdbase.org/.

[218] Igarashi Y, Nakatsu N, Yamashita T, et al. Open TG-GATEs: a large-scale toxicogenomics database. Nucleic Acids Res. 2015;43:D921-D927.

[219] NIBIOHN - National Institutes of Biomedical Innovation Health and Nutrition. Open TG-GATES [Internet]. 2018 [cited 2018 Sep 17]. Available from: http://toxico.nibiohn.go.jp/english/.

[220] U.S. Environmental Protection Agency (EPA). ToxCast ${ }^{\mathrm{TM}}$ Dashboard [Internet]. 2017 [cited 2017 Nov 28]. Available from: https://actor.epa.gov/dashboard/.

[221] Nelms MD, Mellor CL, Angrish MM, et al. Using adverse outcome pathways to build chemical groups: a case study for hepatic steatosis. [Poster] SOT. Baltimore, USA, 12-16 March 2017; 2017.

[222] Judson RS, Houck KA, Kavlock RJ, et al. In vitro screening of environmental chemicals for targeted testing prioritization: the ToxCast project. Environ. Health Perspect. 2010;118:485492.

[223] Judson RS, Kavlock RJ, Setzer RW, et al. Estimating toxicity-related biological pathway altering doses for high-throughput chemical risk assessment. Chem. Res. Toxicol. 2011;24:451-462.

[224] Martin MT, Knudsen TB, Reif DM, et al. Predictive model of rat reproductive toxicity from ToxCast high throughput screening. Biol. Reprod. [Internet]. 2011;85:327-339. Available from: https://academic.oup.com/biolreprod/articlelookup/doi/10.1095/biolreprod.111.090977.

[225] Thomas RS, Black MB, Li L, et al. A comprehensive statistical analysis of predicting in vivo hazard using high-throughput in vitro screening. Toxicol. Sci. 2012;128:398-417.

[226] Browne P, Judson RS, Casey WM, et al. Screening chemicals for estrogen receptor bioactivity using a computational model. Environ. Sci. Technol. 2015;49:8804-8814.

[227] Janesick AS, Dimastrogiovanni G, Vanek L, et al. On the utility of ToxCast ${ }^{\mathrm{TM}}$ and ToxPi as methods for identifying new obesogens. Environ. Health Perspect. 2016;124:1214-1226.

[228] Houck KA, Judson RS, Knudsen TB, et al. Comment on "On the utility of ToxCast ${ }^{\mathrm{TM}}$ and ToxPi as methods for identifying new obesogens. Environ. Health Perspect. 2017;125:A8-A11.

[229] Janesick AS, Dimastrogiovanni G, Chamorro-García R, et al. Reply to "Comment on 'On the utility of ToxCast ${ }^{\mathrm{TM}}$ and ToxPi as methods for identifying new obesogens."' Environ. Health Perspect. 2017;125:A12-A14.

[230] U.S. National Library of Medicine (NLM). HSDB: a TOXNET database [Internet]. 2017 [cited 2017 Dec 19]. Available from: https://toxnet.nlm.nih.gov/newtoxnet/hsdb.htm. 
[231] Morrissey KM, Wen CC, Johns SJ, et al. The UCSF-FDA TransPortal: a public drug transporter database. Clin. Pharmacol. Ther. 2012;92:545-546.

[232] University of California San Francisco (UCSF). UCSF-FDA TransPortal [Internet]. [cited 2018 Sep 17]. Available from: http://transportal.compbio.ucsf.edu/.

[233] Buzhor E, Harari-Steinberg O, Omer D, et al. Kidney spheroids recapitulate tubular organoids leading to enhanced tubulogenic potency of human kidney-derived cells. Tissue Eng. Part A [Internet]. 2011;17:2305-2319. Available from:

http://www.liebertonline.com/doi/abs/10.1089/ten.tea.2010.0595.

[234] Freedman BS, Brooks CR, Lam AQ, et al. Modelling kidney disease with CRISPR-mutant kidney organoids derived from human pluripotent epiblast spheroids. Nat. Commun. [Internet]. 2015;6:8715. Available from: http://dx.doi.org/10.1038/ncomms9715.

[235] Xu Y, Shi T, Xu A, et al. 3D spheroid culture enhances survival and therapeutic capacities of MSCs injected into ischemic kidney. J. Cell. Mol. Med. 2016;20:1203-1213.

[236] Fisher RL, Sanuik JT, Gandolfi AJ, et al. Toxicity of cisplatin and mercuric chloride in human kidney cortical slices. Hum. Exp. Toxicol. 1994;13:517-523.

[237] Vickers AEM, Rose K, Fisher R, et al. Kidney slices of human and rat to characterize cisplatininduced injury on cellular pathways and morphology. Toxicol. Pathol. 2004;32:577-590.

[238] Kusuhara $\mathrm{H}$, Sugiyama Y. In vitro-in vivo extrapolation of transporter-mediated clearance in the liver and kidney. Drug Metab. Pharmacokinet. [Internet]. 2009;24:37-52. Available from: http://www.ncbi.nlm.nih.gov/pubmed/19252335.

[239] Watanabe $\mathrm{T}$, Kusuhara $\mathrm{H}$, Watanabe $\mathrm{T}$, et al. Prediction of the overall renal tubular secretion and hepatic clearance of anionic drugs and a renal drug-drug interaction involving organic anion transporter 3 in humans by in vitro uptake experiments. Drug Metab. Dispos. 2011;39:1031-1038.

[240] Watanabe T, Kusuhara H, Maeda K, et al. Investigation of the rate-determining process in the hepatic elimination of HMG-CoA reductase inhibitors in rats and humans. Drug Metab. Dispos. 2010;38:215-222.

[241] Yang C, Hristozov D, Tarkhov A, et al. COSMOS DB as an international share point for exchanging regulatory and toxicity data of cosmetics ingredients and related substances. Toxicol. Lett. 2015;238:S382-S382.

[242] MN-AM. COSMOS Database [Internet]. Molecular Networks GmbH, Germany. Altamira, LLC, USA. 2018 [cited 2018 Sep 17]. Available from: http://www.cosmostox.eu/what/COSMOSdb/.

[243] Bitsch A, Jacobi S, Melber C, et al. REPDOSE: a database on repeated dose toxicity studies of commercial chemicals - a multifunctional tool. Regul. Toxicol. Pharmacol. 2006;46:202-210. 
[244] Fraunhofer ITEM. RepDose online [Internet]. 2018 [cited 2018 Sep 17]. Available from: https://repdose.item.fraunhofer.de/.

[245] Urinary Protein Biomarker (UPB) database (Chinese) [Internet]. [cited 2018 Sep 17]. Available from: http://bmicc.cn/web/share/search/hupd.

[246] U.S. National Library of Medicine (NLM). ClinicalTrials.gov [Internet]. 2017 [cited 2018 Feb 28]. Available from: https://clinicaltrials.gov/.

[247] FDAble LLC. FDAble: MedWatch Drug Adverse Events (FAERS / AERS) [Internet]. 2017 [cited 2017 Dec 19]. Available from: http://www.fdable.com/basic_query/aers.

[248] U.S. Food and Drug Administration (FDA). Questions and answers on FDA's Adverse Event Reporting System (FAERS) [Internet]. 2017 [cited 2017 Dec 19]. Available from: https://www.fda.gov/Drugs/GuidanceComplianceRegulatorylnformation/Surveillance/Advers eDrugEffects/.

[249] European Medicines Agency (EMA). EudraVigilance - European database of suspected adverse drug reaction reports [Internet]. 2018 [cited 2018 Sep 17]. Available from: http://www.adrreports.eu/.

[250] Tong W, Xie Q, Hong H, et al. Assessment of prediction confidence and domain extrapolation of two structure-activity relationship models for predicting estrogen receptor binding activity. Environ. Health Perspect. 2004;112:1249-1254.

[251] Low $Y$, Uehara T, Minowa $Y$, et al. Predicting drug-induced hepatotoxicity using QSAR and toxicogenomics approaches. Chem. Res. Toxicol. 2011;24:1251-1262.

[252] Lee S, Kang Y-M, Park H, et al. Human nephrotoxicity prediction models for three types of kidney injury based on data sets of pharmacological compounds and their metabolites. Chem. Res. Toxicol. 2013;26:1652-1659.

[253] Cronin MTD, Madden JC, editors. In silico toxicology: principles and applications [Internet]. Cambridge: Royal Society of Chemistry; 2010. Available from: http://ebook.rsc.org/?DOI=10.1039/9781849732093.

[254] McKinney JD, Richard A, Waller C, et al. The practice of structure activity relationships (SAR) in toxicology. Toxicol. Sci. [Internet]. 2000;56:8-17. Available from: http://www.toxsci.oupjournals.org/cgi/doi/10.1093/toxsci/56.1.8.

[255] Enoch SJ, Ellison CM, Schultz TW, et al. A review of the electrophilic reaction chemistry involved in covalent protein binding relevant to toxicity. Crit. Rev. Toxicol. [Internet]. 2011;41:783-802. Available from: http://www.tandfonline.com/action/journallnformation?journalCode=itxc20.

[256] Ellison CM, Enoch SJ, Cronin MTD. A review of the use of in silico methods to predict the 
chemistry of molecular initiating events related to drug toxicity. Expert Opin. Drug Metab. Toxicol. [Internet]. 2011;7:1481-1495. Available from: http://www.tandfonline.com/doi/full/10.1517/17425255.2011.629186.

[257] Nelms MD, Mellor CL, Cronin MTD, et al. Development of an in silico profiler for mitochondrial toxicity. Chem. Res. Toxicol. [Internet]. 2015;28:1891-1902. Available from: http://pubs.acs.org/doi/10.1021/acs.chemrestox.5b00275.

[258] Claesson A, Minidis A. Systematic approach to organizing structural alerts for reactive metabolite formation from potential drugs. Chem. Res. Toxicol. [Internet]. 2018;acs.chemrestox.8b00046. Available from: http://pubs.acs.org/doi/10.1021/acs.chemrestox.8b00046.

[259] Lapenna S, Fuart-Gatnik M, Worth A. Review of QSAR models and software tools for predicting acute and chronic systemic toxicity. JRC Scientific and Technical Reports, EUR 24639 EN. European Commission Joint Research Centre (JRC) - Institute for Health and Consumer Protection (IHCP) [Internet]. 2010 [cited 2018 Jan 25]. Available from: http://publications.jrc.ec.europa.eu/repository/handle/JRC61930.

[260] Greene N. Computer systems for the prediction of toxicity: an update. Adv. Drug Deliv. Rev. 2002;54:417-431.

[261] MN-AM. ChemTunes - platform and toxicity database [Internet]. Molecular Networks GmbH, Germany. Altamira, LLC, USA. 2018 [cited 2018 Mar 2]. Available from: https://www.mnam.com/products/chemtunes.

[262] Munday R, Smith BL, Munday CM. Structure-activity relationships in the haemolytic activity and nephrotoxicity of derivatives of 1,2- and 1,4-naphthoquinone. J. Appl. Toxicol. 2007;27:262-269.

[263] Pizzo F, Gadaleta D, Lombardo A, et al. Identification of structural alerts for liver and kidney toxicity using repeated dose toxicity data. Chem. Cent. J. 2015;9:1-11.

[264] Chilton ML, Macmillan DS, Steger-Hartmann T, et al. Making reliable negative predictions of human skin sensitisation using an in silico fragmentation approach. Regul. Toxicol. Pharmacol. [Internet]. 2018;95:227-235. Available from: https://www.sciencedirect.com/science/article/pii/S0273230018300886.

[265] Myshkin E, Brennan R, Khasanova T, et al. Prediction of organ toxicity endpoints by QSAR modeling based on precise chemical-histopathology annotations. Chem. Biol. Drug Des. 2012;80:406-416.

[266] Jolivette L, Anders MW. Structure-activity relationships for the biotransformation of haloalkenes by rat liver microsomal glutathione transferase 1 . Chem. Res. Toxicol. 
2002;15:1036-1041.

[267] Matthews EJ, Ursem CJ, Kruhlak NL, et al. Identification of structure-activity relationships for adverse effects of pharmaceuticals in humans: part $B$. Use of (Q)SAR systems for early detection of drug-induced hepatobiliary and urinary tract toxicities. Regul. Toxicol. Pharmacol. [Internet]. 2009;54:23-42. Available from: http://dx.doi.org/10.1016/j.yrtph.2009.01.009.

[268] Antczak P, Ortega F, Chipman JK, et al. Mapping drug physico-chemical features to pathway activity reveals molecular networks linked to toxicity outcome. PLoS One. 2010;5:e12385.

[269] Hammann F, Gutmann H, Vogt N, et al. Prediction of adverse drug reactions using decision tree modeling. Clin. Pharmacol. Ther. [Internet]. 2010;88:52-59. Available from: http://dx.doi.org/10.1038/clpt.2009.248.

[270] Lei T, Sun H, Kang Y, et al. ADMET evaluation in drug discovery. 18. Reliable prediction of chemical-induced urinary tract toxicity by boosting machine learning approaches. Mol. Pharm. 2017;14:3935-3953.

[271] Munday R, Smith BL, Fowke EA. Haemolytic activity and nephrotoxicity of 2-hydroxy-1,4naphthoquinone in rats. J. Appl. Toxicol. 1991;11:85-90.

[272] Munday R, Smith BL, Munday CM. Effect of inducers of DT-diaphorase on the haemolytic activity and nephrotoxicity of 2-amino-1,4-naphthoquinone in rats. Chem. Biol. Interact. 2005;155:140-147.

[273] Devecioğlu C, Katar S, Doğru O, et al. Henna-induced hemolytic anemia and acute renal failure. Turk. J. Pediatr. [Internet]. 2001;43:65-66. Available from: http://www.ncbi.nlm.nih.gov/pubmed/11297162.

[274] Lovecka P, Thimova M, Grznarova P, et al. Study of cytotoxic effects of benzonitrile pesticides. Biomed Res. Int. 2015;2015:article ID 381264, 9 pages.

[275] Ohnishi M, Yajima H, Takeuchi T, et al. Mechanism of urinary tract crystal formation following biphenyl treatment. Toxicol. Appl. Pharmacol. 2001;174:122-129.

[276] Bomhard E, Marsmann M, Rühl-Fehlert C, et al. Relationships between structure and induction of hyaline droplet accumulation in the renal cortex of male rats by aliphatic and alicyclic hydrocarbons. Arch. Toxicol. 1990;64:530-538.

[277] Tang-Liu DD-S, Tozer TN, Riegelman S. Dependence of renal clearance on urine flow: a mathematical model and its application. J. Pharm. Sci. 1983;72:154-158.

[278] Hall S, Rowland M. Relationship between renal clearance, protein binding and urine flow for digitoxin, a compound of low clearance in the isolated perfused rat kidney. J. Pharmacol. Exp. Ther. 1984;228:174-179. 
[279] Komiya I. Urine flow dependence of renal clearance and interrelation of renal reabsorption and physicochemical properties of drugs. Drug Metab. Dispos. 1986;14:239-245.

[280] Komiya I. Urine flow-dependence and interspecies variation of the renal reabsorption of sulfanilamide. J. Pharmacobiodyn. [Internet]. 1987;10:1-7. Available from: http://www.ncbi.nlm.nih.gov/pubmed/3585691.

[281] Mayer JM, Hall SD, Rowland M. Relationship between lipophilicity and tubular reabsorption for a series of 5-alkyl-5-ethylbarbituric acids in the isolated perfused rat kidney preparation. J. Pharm. Sci. 1988;77:359-364.

[282] Russel FGM, Wouterse AC, van Ginneken CAM. Physiologically based pharmacokinetic model for the renal clearance of salicyluric acid and the interaction with phenolsulfonphthalein in the dog. Drug Metab. Dispos. [Internet]. 1987;15:695-701. Available from: http://www.ncbi.nlm.nih.gov/pubmed/2891488.

[283] Russel FGM, Wouterse AC, van Ginneken CAM. Physiologically based pharmacokinetic model for the renal clearance of phenolsulfonphthalein and the interaction with probenecid and salicyluric acid in the dog. J. Pharmacokinet. Biopharm. 1987;15:349-368.

[284] Russel FGM, Wouterse AC, Hekman P, et al. Quantitative urine collection in renal clearance studies in the dog. J. Pharmacol. Methods [Internet]. 1987;17:125-136. Available from: http://linkinghub.elsevier.com/retrieve/pii/0160540287900234.

[285] Katayama K, Ohtani H, Kawabe T, et al. Kinetic studies on drug disposition in rabbits. I. Renal excretion of iodopyracet and sulfamethizole. J. Pharmacobiodyn. [Internet]. 1990;13:97-107. Available from: http://joi.jlc.jst.go.jp/JST.Journalarchive/bpb1978/13.97?from=CrossRef.

[286] Felmlee MA, Wang $Q$, Cui D, et al. Mechanistic toxicokinetic model for $\psi$-hydroxybutyric acid: inhibition of active renal reabsorption as a potential therapeutic strategy. AAPS J. [Internet]. 2010;12:407-416. Available from: http://www.springerlink.com/index/10.1208/s12248-0109197-x.

[287] Felmlee MA, Dave RA, Morris ME. Mechanistic models describing active renal reabsorption and secretion: a simulation-based study. AAPS J. [Internet]. 2013;15:278-287. Available from: http://www.springerlink.com/index/10.1208/s12248-012-9437-3.

[288] Layton AT. Mathematical modeling of kidney transport. Wiley Interdiscip. Rev. Syst. Biol. Med. 2013;5:557-573.

[289] Palm F, Nordquist L. Renal tubulointerstitial hypoxia: cause and consequence of kidney dysfunction. Clin. Exp. Pharmacol. Physiol. 2011;38:474-480.

[290] Fu Q, Colgan SP, Shelley CS. Hypoxia: the force that drives chronic kidney disease. Clin. Med. Res. 2016;14:15-39. 
[291] Gutsell S, Russell P. The role of chemistry in developing understanding of adverse outcome pathways and their application in risk assessment. Toxicol. Res. (Camb). [Internet]. 2013;2:299-307. Available from: http://xlink.rsc.org/?DOI=c3tx50024a.

[292] Pletz J, Ebbrell DJ, Enoch SJ, et al. Development of a robust in silico profiler to screen for nephrotoxicity endpoints. Toxicol. Lett. 2018;295:S97.

[293] Madden J, Pletz J, Webb S, et al. Identifying potential liver toxicants using in vitro and in silico methods in a weight-of-evidence based approach. Toxicol. Lett. [Internet]. 2017;280:S133. Available from: http://linkinghub.elsevier.com/retrieve/pii/S0378427417306069.

[294] Vinken M, Blaauboer BJ. In vitro testing of basal cytotoxicity: establishment of an adverse outcome pathway from chemical insult to cell death. Toxicol. Vitr. 2017;39:104-110. 